\title{
Zinc-induced cardiomyocyte relaxation in a rat model of hyperglycemia is independent of myosin isoform
}

Ting $\mathrm{Yi}^{1+}$, Yaser Cheema ${ }^{2+}$, Sarah M Tremble ${ }^{2}$, Stephen P Bell², Zengyi Chen², Meenakumari Subramanian', Martin M LeWinter ${ }^{1,2}$, Peter VanBuren ${ }^{1,2}$ and Bradley M Palmer ${ }^{1 *}$

\begin{abstract}
It has been reported previously that diabetic cardiomyopathy can be inhibited or reverted with chronic zinc supplementation. In the current study, we hypothesized that total cardiac calcium and zinc content is altered in early onset diabetes mellitus characterized in part as hyperglycemia $(\mathrm{HG})$ and that exposure of zinc ion $\left(\mathrm{Zn}^{2+}\right)$ to isolated cardiomyocytes would enhance contraction-relaxation function in $\mathrm{HG}$ more so than in nonHG controls. To better control for differential cardiac myosin isoform expression as occurs in rodents after $\beta$-islet cell necrosis, hypothyroidism was induced in 16 rats resulting in $100 \% \beta$-myosin heavy chain expression in the heart. $\beta$-Islet cell necrosis was induced in half of the rats by streptozocin administration. After 6 wks of HG, both HG and nonHG controls rats demonstrated similar myofilament performance measured as thin filament calcium sensitivity, native thin filament velocity in the myosin motility assay and contractile velocity and power. Extracellular $\mathrm{Zn}^{2+}$ reduced cardiomyocyte contractile function in both groups, but enhanced relaxation function significantly in the HG group compared to controls. Most notably, a reduction in diastolic sarcomere length with increasing pacing frequencies, i.e., incomplete relaxation, was more pronounced in the HG compared to controls, but was normalized with extracellular $\mathrm{Zn}^{2+}$ application. This is a novel finding implicating that the detrimental effect of HG on cardiomyocyte $\mathrm{Ca}^{2+}$ regulation can be amelioration by $\mathrm{Zn}^{2+}$. Among the many post-translational modifications examined, only phosphorylation of ryanodine receptor (RyR) at S-2808 was significantly higher in HG compared to nonHG. We did not find in our hypothyroid rats any differentiating effects of $\mathrm{HG}$ on myofibrillar protein phosphorylation, lysine acetylation, O-linked N-acetylglucosamine and advanced glycated end-products, which are often implicated as complicating factors in cardiac performance due to $\mathrm{HG}$. Our results suggest that the relaxing effects of $\mathrm{Zn}^{2+}$ on cardiomyocyte function are more pronounced in the HG state due an insulin-dependent effect of enhancing removal of cytosolic $\mathrm{Ca}^{2+}$ via SERCA2a or NCX or by reducing $\mathrm{Ca}^{2+}$ influx via L-type channel or $\mathrm{Ca}^{2+}$ leak through the RyR. Investigations into the effects of $\mathrm{Zn}^{2+}$ on these mechanisms are now underway.
\end{abstract}

Keywords: Streptozotocin, PTU, Type 1 diabetes, Cardiac, Iron, Sulfur

\section{Background}

The term diabetic cardiomyopathy refers to a state of cardiac dysfunction independent of associated coronary artery disease that arises within weeks of hyperglycemia (HG) leading to longer term diabetes mellitus (DM) [1]. Diabetic cardiomyopathy in humans and animals is

\footnotetext{
*Correspondence: bmpalmer@uvm.edu

${ }^{\dagger}$ Equal contributors

'Department of Molecular Physiology and Biophysics, University of Vermont, 122 HSRF Beaumont Ave, Burlington VT 05405, USA

Full list of author information is available at the end of the article
}

characterized in part by elevated end-diastolic left ventricular (LV) pressure, reduced end-diastolic LV volume, impaired augmentation of LV function in response to physiological stresses, reduced phosphocreatine resources and reduced LV filling rates [1-5]. Patients with diabetic cardiomyopathy often experience exertional dyspnea and a higher incidence of hospitalization due to heart failure. Currently there are no proven effective treatments for long term management of diabetic cardiomyopathy.

\section{() Biomed Central}

(c) 2012 Yi et al.; licensee BioMed Central Ltd. This is an Open Access article distributed under the terms of the Creative Commons Attribution License (http://creativecommons.org/licenses/by/2.0), which permits unrestricted use, distribution, and reproduction in any medium, provided the original work is properly cited. 
Cardiomyopathic effects in rodents or rabbits with HG or type $1 \mathrm{DM}$ induced by treatments targeting pancreatic $\beta$-islet cells $[6,7]$ are characterized at the cardiomyocyte level by depressed adrenergic responsiveness [8,9], prolonged action potential duration [10,11], reduced or delayed calcium influx through sarcolemmal L-type channels [10], reduced SERCA2a content and calcium reuptake rate $[11,12]$, greater calcium ion $\left(\mathrm{Ca}^{2+}\right)$ leak through the sarcoplasmic reticulum (SR) release channels also called ryanodine receptors (RyR) [13-15], elevated cytosolic $\mathrm{Ca}^{2+}$ in diastole [15], and reduced function yet elevated content of mitochondria [16]. These and other findings indicate a broad spectrum of cellular and molecular mechanisms that underlie the elevated morbidity and mortality associated with diabetic cardiomyopathy $[1,2]$.

The development of diabetic cardiomyopathy after 6 months of DM in mice is inhibited or reversed by the chronic administration of zinc [17]. While the cellular and molecular mechanisms responsible for zinc-induced protection against diabetic cardiomyopathy are not fully understood, there is evidence that the zinc-binding protein metallothionein (MT) plays a role in protection against oxidative stress associated with diabetic cardiomyopathy [17-20]. While MT expression may be important for long term protection against oxidative stress, zinc also appears protective against oxidative stress in the short term such as in ischemia-reperfusion injury $[21,22]$. How zinc provides MT-independent cardioprotection is not well understood. It is known that extracellular zinc ion $\left(\mathrm{Zn}^{2+}\right)$ competes with $\mathrm{Ca}^{2+}$ for the cardiomyocyte L-type calcium channel [23,24]. In addition, release of $\mathrm{SR} \mathrm{Zn}^{2+}$ through the ryanodine receptors (RyR) also appears to be regulated similarly to that of SR $\mathrm{Ca}^{2+}[25]$. Thus, the balance of calcium and zinc regulation would be a logical focus of inquiry in determining the underling mechanisms responsible for the protective effects of zinc during the development of diabetic cardiomyopathy.

Hypothyroidism accompanies experimental HG and $\mathrm{DM}$ and leads to the upregulation of cardiac $\beta$-myosin heavy chain $(\mathrm{MyHC})$ in rodents [26-29]. The slow $\beta-\mathrm{MyHC}$ isoform can significantly diminish cardiac contractionrelaxation function compared to controls, which normally expressing the faster $\alpha-\mathrm{MyHC}$ isoform [5,30-32]. Thus, this and other secondary effects of HG and DM on diminished thyroid status must not be erroneously attributed to primary insulin-dependent effects [26].

In the present study, we hypothesized that extracellular zinc ameliorates cardiomyocyte dysfunction symptomatic of the development of diabetic cardiomyopathy in rats with HG. To obviate complications of variable $\mathrm{MyHC}$ isoform expression after $\beta$-islet necrosis [29], we induced HG in hypothyroid rats expressing 100\%
$\beta$-MyHC. We found that cardiomyocyte contraction function was enhanced by HG, but relaxation function was reduced by HG. Exposure to extracellular $\mathrm{Zn}^{2+}$ reduced contraction function in both HG and nonHG controls, but enhanced relaxation function only in the HG. Our findings are consistent with intracellular $\mathrm{Ca}^{2+}$ overload with $\mathrm{HG}$ and $\mathrm{DM}$ at the cellular level that can be reduced by exposure to $\mathrm{Zn}^{2+}$.

\section{Methods \\ Rat model}

All procedures were reviewed and approved by the Institutional Animal Care and Use Committee of The University of Vermont College of Medicine and complied with the Guide for the Use and Care of Laboratory Animals published by the National Institutes of Health. Sixteen male Wistar rats (Charles River Laboratories) were fed an iodine-deficient $0.15 \%$ 6-n-propyl-2-thiouracil (PTU) diet (Harlan Teklan) for at least 12 weeks. After 6 weeks on the diet, eight rats received tail vein injection of $50 \mathrm{mg} / \mathrm{g} \mathrm{STZ}$ prepared in sodium citrate solution. The remaining rats received injection of similar volume of vehicle. At least 6 weeks after induction of HG by STZ, rats were anesthetized with $1.5-3 \%$ inhaled isoflurane, and short-axis view M-mode echocardiography was performed using Acuson Sequoia C256 (Seimens Medical Solutions) fitted with a $15 \mathrm{MHz}$ probe suitable for resolving dimensions of the rat heart. Hearts were removed, and subjects died of exsanguination. Papillary muscles were then taken for myofilament performance assessment, apexes were harvested for elemental analysis and cardiomyocytes were isolated from the remaining $\mathrm{LV}$.

\section{Echocardiography}

Measures of heart size and function included heart rate, left ventricular posterior wall thickness (LVPWT), left ventricular diameter at end-diastole (LVD dias) and endsystole (LVD sys), fractional shortening $=($ LVD dias - LVD sys $) /$ LVD dias, ejection fraction $=\left(\right.$ LVD $\operatorname{dias}^{3}-$ LVD sys $\left.^{3}\right) /$ LVD $\operatorname{dias}^{3}$, ejection time taken between QRS complex and peak shortening, and circumferential velocity $=$ fractional shortening/ejection time.

\section{Solutions for skinned myocardial strips}

Solution concentrations $(\mathrm{mmol} / \mathrm{L})$ were formulated by solving equations describing ionic equilibria [33]. Relaxing solution: pCa 8.0, 5 EGTA, 5 MgATP, $1 \mathrm{Mg}^{2+}, 35$ phosphocreatine (PCr), $300 \mathrm{U} / \mathrm{mL}$ creatine kinase (CK), ionic strength 200, $\mathrm{pH}$ 7.0. Activation solution: same as relaxing with $\mathrm{pCa}$ 4.0. Storage solution: same as relaxing with $10 \mu \mathrm{g} / \mathrm{mL}$ leupeptin and $50 \%$ glycerol wt/vol. 


\section{Skinned myocardial strips}

Skinned myocardial strips were studied as previously described [34]. Papillary muscles from the LV were dissected to yield at least two thin strips $(\sim 140 \mu \mathrm{m}$ diameter, $\sim 800 \mu \mathrm{m}$ length) with longitudinally oriented parallel fibers, skinned for $2 \mathrm{hr}$ at $22^{\circ} \mathrm{C}$, and stored at $-20^{\circ} \mathrm{C}$. Aluminum T-clips were attached to the ends of a strip $\sim 300 \mu \mathrm{m}$ apart. The strip was mounted between a piezoelectric motor (Physik Instrumente, Auburn, MA) and a strain gauge (SensorNor, Horten, Norway), lowered into a $30 \mu \mathrm{L}$ droplet of relaxing solution ( $\mathrm{pCa} 8.0$ ) maintained at $37^{\circ} \mathrm{C}$, and incrementally stretched to $2.2 \mu \mathrm{m}$ sarcomere length measured by digital Fourier Transform (IonOptix Corp, Milton, MA). Strips were calcium activated from $\mathrm{pCa} 8.0$ to $\mathrm{pCa} 4.8$.

Recorded forces were normalized to cross-sectional area to provide isometric tension ( $\mathrm{T}$ ). Individual recordings of $\mathrm{T}$ minus relaxed tension $\left(\mathrm{T}_{\min }\right)$ were then normalized to maximum developed tension $\left(\mathrm{T}_{\max }-\mathrm{T}_{\min }\right)$ and fit to the Hill equation:

$$
\begin{aligned}
(\mathrm{T} & \left.-\mathrm{T}_{\min }\right) /\left(\mathrm{T}_{\max }-\mathrm{T}_{\min }\right) \\
& =\left[\mathrm{Ca}^{2+}\right]^{\mathrm{n}} /\left(\left[\mathrm{Ca}^{2+}\right]_{50}{ }^{\mathrm{n}}+\left[\mathrm{Ca}^{2+}\right]^{\mathrm{n}}\right),
\end{aligned}
$$

where $\left[\mathrm{Ca}^{2+}\right]_{50}=$ calcium concentration at half activation, $\mathrm{pCa}_{50}=-\log \left[\mathrm{Ca}^{2+}\right]_{50}$, and $\mathrm{n}=$ Hill coefficient using a nonlinear least squares algorithm (Sigma Plot 8.0, SPSS, Chicago, IL).

\section{Tension-velocity relationship}

The force-clamp technique was applied at maximal calcium activation. Various mechanical loads were expressed as a fraction of maximum absolute tension $\left(\mathrm{T}_{\max }\right)$. Force was maintained constant over a designated period of time using software-based feedback control, and the length change was continuously monitored. The tensionvelocity (T-V) relationship was generated from these data.

The relationship was fit to a hyperbolic Hill equation normalized to $\mathrm{T}_{\max }$ :

$$
\left(\mathrm{T}^{\prime}+\mathrm{a}^{\prime}\right)(\mathrm{V}+\mathrm{b})=\left(1+\mathrm{a}^{\prime}\right) \mathrm{b}
$$

where $T^{\prime}=T / T_{\max }, a^{\prime}=a / T_{\max }$, and $a$ and $b$ are the parameters of the non-normalized hyperbolic Hill equation using a nonlinear least squares algorithm (Sigma Plot 8.0, SPSS, Chicago, IL). The physiological characteristics maximum unloaded shortening velocity $\left(\mathrm{V}_{\max }\right)$, velocity at maximum power $\left(\mathrm{V}_{\mathrm{opt}}\right)$, tension at maximum power $\left(\mathrm{T}^{\prime}{ }_{\text {opt }}\right)$ and maximum power production $\left(\mathrm{P}_{\max }\right)$ were calculated from $\mathrm{a}$ and $\mathrm{b}$, as follows [31,32]:

$$
\begin{aligned}
\mathrm{V}_{\max }= & \mathrm{b} / \mathrm{a}^{\prime}(\mathrm{ML} / \mathrm{s}) \\
\mathrm{V}_{\text {opt }}= & \mathrm{b}\left(1+1 / \mathrm{a}^{\prime}\right)^{1 / 2}-\mathrm{a}^{\prime}(\mathrm{ML} / \mathrm{s}) \\
\mathrm{T}_{\text {opt }}^{\prime}= & \left(\mathrm{a}^{\prime 2}+\mathrm{a}^{\prime}\right)^{1 / 2}-\mathrm{a}^{\prime}\left(\text { fraction of } \mathrm{T}_{\max }\right) \\
\mathrm{P}_{\max }= & \left(1-\mathrm{T}_{\text {opt }}^{\prime}\right) \mathrm{bT}_{\text {opt }}^{\prime} /\left(\mathrm{a}^{\prime}+\mathrm{T}_{\text {opt }}^{\prime}\right) \\
& \left(\text { fraction of } \mathrm{T}_{\max } \cdot \mathrm{ML} / \mathrm{s}\right),
\end{aligned}
$$

\section{Native thin filament isolation}

Intact native thin filaments were isolated from ventricular tissue as described previously [35]. In brief, myofibrils were isolated from flash frozen muscle tissue and subsequently homogenized in the following solution (in mmol/L): $100 \mathrm{NaCl}, 5 \mathrm{MgCl}_{2}, 1 \mathrm{NaN}_{3}, 1$ ethylene glycol tetraacetic acid (EGTA), $5 \mathrm{MgATP}, 10 \mathrm{Na}_{3} \mathrm{PO}_{4}$ and $2 \mu \mathrm{g} /$ $\mathrm{ml}$ leupeptin at a ratio $40 \mathrm{ml} / \mathrm{gm}$ of myofibril ( $\mathrm{pH} 6.5)$. Debris and thick filament were pelleted with centrifugation $137,000 \times \mathrm{g}$ for 20 minutes. Native thin filaments were then collected with centrifugation $(137,000 \mathrm{x} g$ for 180 minutes) with the pellet being raised in low salt buffer (in mmol/L): $25 \mathrm{KCl}, 25$ imidazole, 1 EGTA, 5 $\mathrm{MgCl}_{2}, 10$ DTT. Protein concentration was determined for native thin filaments with a protein assay (Bio-Rad; Hercules, CA, USA) using bovine serum albumin as the standard. Chicken skeletal myosin was isolated as previously described. Chicken skeletal myosin was used as the motility substrate in the in vitro motility assay due to its temporal stability, creating consistency between experiments [35]. Native thin filaments were labeled with rhodamine-phalloidin (1:1 molar ratio) prior to use in the motility assay.

\section{In vitro motility assay}

Native thin filament contractile performance was assessed using the in vitro motility as described previously [36]. In brief, myosin $(100 \mu \mathrm{g} / \mathrm{ml}$, unless otherwise noted) was applied for one minute to a nitrocellulose coated coverslip in a high salt buffer (in mmol/L): 300 $\mathrm{KCl}, 25$ imidazole, $5 \mathrm{MgCl}_{2}$, 2 EGTA and $10 \mathrm{DTT}$. The surface was then washed with bovine serum albumin $(0.5 \mathrm{mg} / \mathrm{ml})$ in low salt buffer. Employing epifluorescent microscopy, rhodamine-labeled thin filaments were observed moving across the myosin coated surface in the presence of MgATP $(2 \mathrm{mmol} / \mathrm{L})$ in a buffered motility solution (in mmol/L unless otherwise noted): $25 \mathrm{KCl}$, 25 imidazole, $5 \mathrm{MgCl}_{2}, 2$ EGTA and 10 DTT, glucose oxidase $0.1 \mathrm{mg} / \mathrm{ml}$, catalase $1.8 \mu \mathrm{g} / \mathrm{ml}$, glucose $2.3 \mathrm{mg} /$ $\mathrm{ml}$, and $0.38 \%$ methylcellulose. Free calcium was varied in the motility solution ( $\mathrm{pCa} 10-4.0)$. Thin filament motility was recorded on videotape, and subsequently analyzed with the motion analysis system VP110 (Motion 
Analysis Corporation, Santa Rosa, CA). Typically $>300$ individual filament velocities were averaged to determine the mean velocity of each experiment. All motility experiments were performed at $30^{\circ} \mathrm{C}$.

\section{Isolated cardiomyocyte function}

Rat LV cardiomyocytes were isolated using retrograde perfusion of collagenase solution according to methods described elsewhere [37]. Cardiomyocytes were observed with a $40 \times$ objective on an inverted microscope (Nikon Diaphot) while bathed in normal Tyrode's solution containing in mmol/L: $137 \mathrm{NaCl}, 5.4 \mathrm{KCl}, 1.2 \mathrm{CaCl}_{2}, 0.5$ $\mathrm{MgCl}_{2}, 10 \mathrm{HEPES}, 5.5$ glucose, 0.5 probenecid at $37^{\circ} \mathrm{C}$ (pH 7.4). Cardiomyocytes were electrically paced at 2,4 and $6 \mathrm{~Hz}$ for at least 5 minutes at each frequency. Half of the cardiomyocytes were exposed to Tyrode's with $32 \mu \mathrm{M} \mathrm{Zn}$-acetate. Dynamic sarcomere length was detected by Fourier Transform of the digital image.

A subset of cardiomyocytes from each heart was loaded with Fura-2 AM (Invitrogen, Carlsbad, CA) and excited at $365 \mathrm{~nm}$ and $400 \mathrm{~nm}$. Emission at $510 \mathrm{~nm}$ was used to detect Fura-2 fluorescence at each pacing frequency, although not with zinc exposure. We did not measure intracellular $\mathrm{Ca}^{2+}$ during $\mathrm{Zn}^{2+}$ exposure, because Fura- 2 is sensitive to both physiological $\mathrm{Zn}^{2+}$ and $\mathrm{Ca}^{2+}[23]$ and we would not have been able to differentiate the two ions. Background fluorescence was detected after lysing cardiomyocytes with $4 \mu \mathrm{M}$ digitonin. Parameters of fluorescence ratio 365/400 (R) dynamics were used to represent those of calcium dynamics [38].

\section{Myosin isoform determination and western blots}

Ventricular myosin isoform content of HG and nonHG rats was determined by the method of Reiser and Kline [39] with the use of Fluormax-2 Imaging analysis (Bio-Rad, Hercules, CA). Protein phosphorylation stain (Pro-Q diamond, Invitrogen) and Western blots for myosin regulatory light chain (MLC2) content (cat. ab92721, Abcam, San Francisco, CA), MLC2 phosphorylation (MLC2-P) at Serine-19 (cat. ab2480, Abcam), RyR (cat. MA3-916, Thermo Scientific), RYR phosphorylation at Serine-2808/9 (cat. A010-30AP, Badrilla), Olinked N-Acetylglucosamine (cat. ab2739, Abcam), lysine acetylation (cat. \#9441, Cell Signaling Technologies) and pentosidine (PEN012, Biologo) were performed using tissue homogenates prepared in $(\mathrm{mmol} / \mathrm{L}) 300 \mathrm{KCl}, 25$ Imidazole, $5 \mathrm{MgCl}_{2}, 2$ EGTA, 10 DTT and $\mathrm{pH}$ 7.4. In some cases, myofilament fraction was extracted as the pellet after centrifugation and non-myofilament fraction as the supernatant.

\section{Cardiac element content measurements}

Polypropylene conical tubes of $15 \mathrm{~mL}$ volume were soaked in $0.4 \mathrm{mM}$ EGTA overnight, then rinsed four times with $\mathrm{ddH}_{2} \mathrm{O}$ and allowed to drip dry according to published recommendations [40]. Between $40-80 \mathrm{mg}$ of each LV sample was placed in its own tube and lyophilized by 90 min of vacuum freeze drying. Samples were digested in $10 \mu \mathrm{L}$ nitric acid (15.8 Normal) per mg tissue wet weight. Gallium was added in the amount $0.2 \mu \mathrm{L}$ of $1 \mathrm{~g} / \mathrm{L} \mathrm{Ga}$ standard per mg tissue wet weight. Finally, ddH2O was added to bring total volume to $200 \times$ dilution of original tissue wet weight including final concentrations of $0.8 \mathrm{~N}$ nitric acid and $1 \mathrm{ppm} \mathrm{Ga}$. Standards were prepared for elements $\mathrm{Ca}, \mathrm{Cu}, \mathrm{Fe}, \mathrm{K}, \mathrm{Mg}, \mathrm{Na}, \mathrm{P}, \mathrm{S}$ and $\mathrm{Zn}$ over ranges $0-0.4 \mathrm{ppm}, 0-4 \mathrm{ppm}$ or $0-40 \mathrm{ppm}$ depending on the element and all including $0.8 \mathrm{~N}$ nitric acid and $1 \mathrm{ppm}$ Ga. Detection of element content was performed using inductively coupled plasma atomic emission spectroscopy (ICP-AES) performed by the ULTIMA2C operated in Poly-mode (Horiba Scientific, Edison, NJ). Element content was detected in triplicate for each sample and normalized against the Ga internal standard to provide a measure of element content in ppm relative to tissue wet weight.

\section{mRNA analysis and quantitative PCR}

Total RNA was extracted from the rat hearts using Qiagen RNeasy kit and cDNA was synthesized using Invitrogen Superscript III first-strand synthesis system according to manufacturer instructions. Taqman primer sets were purchased from Applied Biosystems (Life Technologies): reference numbers HPRT Rn01527840, MT1a Rn00821759, ZnT2 Rn00563633 and $\gamma$-GCSh Rn00689046. Cycle threshold $(\mathrm{Ct})$ values from quantitative RT-PCR were obtained from ABI Prism 7900HT sequence detection system. The mRNA expression levels measured as $\mathrm{Ct}$ were normalized to that of the endogenous control, HPRT, as $\Delta \mathrm{Ct}$. The average $\Delta \mathrm{Ct}$ of the nonHG controls was used as the normalization factor to determine $\Delta \Delta \mathrm{Ct}$ for the HG group. Relative fold difference (RQ) in transcription levels between the HG and nonHG groups was calculated as $\mathrm{RQ}=2^{-\Delta \Delta \mathrm{Ct}}$.

\section{Statistical analysis}

Analysis was performed using PASW Statistics 18.0 (SPSS). Multiple measurements of myofilament performance from the same heart were averaged to provide a single measure for that heart. Tension and actin velocity were normalized to values at maximal calcium activation and fit to the Hill equation using a non-linear least squares algorithm (Sigma Plot 8.0, SPSS, Chicago, IL). Repeated-measures ANOVA, using stimulation frequency within the same cardiomyocyte and zinc exposure within the same heart as repeated measures, was used to detect the relative effects of frequency and zinc exposure between HG and nonHG controls. Data are presented as mean \pm SEM. For function analyses, $n=8$ 
in each group. Significance by statistical tests are reported at the $P<0.05, P<0.01$ and $P<0.001$ levels. Trends at $P<0.1$ are also reported if in support of other statistically significant results.

\section{Results}

\section{Animal characteristics}

STZ induced a dramatic rise in serum glucose concentration in the HG rats, indicative of depressed insulin production by the pancreas (Table 1). Other notable consequences of 6 wks of HG included a reduction in body weight. There were no other highly significant effects of HG in the context of hypothyroidism on cardiac dimension or performance as measured by echocardiography. There was a trend $(P<0.10)$ for a prolonged ejection time with HG, which reflects a prolonged activation of the force-producing myofilaments at the end of systole.

\section{Myofilament performance}

Hypothyroidism inhibited the expression of $\alpha-\mathrm{MyHC}$ and resulted in $100 \% \beta-\mathrm{MyHC}$ incorporation into both HG and nonHG rats as shown in Figure 1A. In euthyroid rats, a similar bout of HG due to STZ resulted in a shift of the myosin isoform profile from a $\sim 85 / 15$ ratio of $\alpha-\mathrm{MyHC} / \beta-\mathrm{MyHC}$ in the nonHG to $\sim 50 / 50$ ratio in the HG (Figure 1A). Unless specified, we examined the hypothyroid rats and thus eliminated the complications of different myosin isoform mixtures [29]. Phosphorylation of myofibrillar proteins and specifically MLC2 were similar between $\mathrm{HG}$ and nonHG control rats (Figure 1B-1D).

Table 1 Rat model characteristics, echo morphometry and serum glucose

\begin{tabular}{lcc}
\hline & HG $(\mathbf{n}=\mathbf{8})$ & nonHG (8) \\
\hline Age (wks) & $19.8 \pm 0.3$ & $20.1 \pm 0.4$ \\
\hline PTU diet (wks) & $12.8 \pm 0.3$ & $13.1 \pm 0.4$ \\
\hline Body mass (g) & $217 \pm 5+$ & $278 \pm 15$ \\
\hline Glucose 1 wks (mg/dL) & $287 \pm 20$ & no measure \\
\hline Glucose 6 wks (mg/dL) & $422 \pm 21+\dagger$ & $75 \pm 6$ \\
\hline Heart rate (bpm) & $213.3 \pm 9.1$ & $229.1 \pm 5.0$ \\
\hline LVD dias (mm) & $6.99 \pm 0.18$ & $6.88 \pm 0.26$ \\
\hline LVD sys (mm) & $4.40 \pm 0.16$ & $4.41 \pm 0.25$ \\
\hline Fractional Shortening (\%) & $37.0 \pm 1.7$ & $35.9 \pm 2.3$ \\
\hline Ejection Fraction (\%) & $74.7 \pm 1.9$ & $73.0 \pm 2.7$ \\
\hline Ejection Time (ms) & $146.6 \pm 5.6 \#$ & $135.8 \pm 2.7$ \\
\hline Circum. Velocity (circ/s) & $2.56 \pm 0.17$ & $2.67 \pm 0.21$ \\
\hline LVPWT dias (mm) & $1.35 \pm 0.09$ & $1.23 \pm 0.09$ \\
\hline Statistical differences by two-tail &
\end{tabular}

Statistical differences by two-tailed $t$-test between $\mathrm{HG}$ and nonHG. $\# P<0.10$, $+P<0.01,++P<0.001$.

\section{Myofilament calcium sensitivity}

Minimum tension, maximal tension and calciumactivated developed tension of skinned myocardial strips were not different between HG and nonHG controls (Table 2). Calcium sensitivity of developed tension, visualized as the normalized tension-calcium relationships in Figure 2A, were indistinguishable between the $\mathrm{HG}$ and nonHG strips at all pCa conditions. The sensitivity of the thin filament to calcium activation, indicated by $\mathrm{pCa}_{50}$, and the cooperativity coefficient, $\mathrm{n}_{\mathrm{Hill}}$, were also unchanged by HG (Table 2).

The velocity-calcium relationships of the native thin filaments (NTF) isolated from the HG and nonHG control rats were indistinguishable from each other (Figure 2B). Parameters for maximal NTF calciumactivated velocity and calcium sensitivity of NTF were also similar in HG and nonHG (Table 2). Moreover, NTF function was not affected by STZ treatment in euthyroid rats (Figure 2B, inset). These results for tensioncalcium and NTF velocity-calcium relationships indicate that thin filament function was not affected by $6 \mathrm{wks}$ of HG in hypothyroid or euthyroid rats.

\section{Tension-velocity relationship}

Examples of clamped force and corresponding length changes, which illustrate the force-clamp technique, are shown in Figures 3A and 3B. Velocity was calculated over 40-60 ms after force-clamp was initiated, which allowed for steady force maintenance and was always within $5 \%$ of the originally set sarcomere length. Tension-velocity and tension-power relationships recorded from forceclamp experiments are shown in Figures 3C and 3D. We found no differences in the velocity- and power-tension relationships between $\mathrm{HG}$ and nonHG controls. Parameters of the maximum velocity, optimum velocity, optimum tension and maximum normalized power production, which are indicators of myofilament contractile performance, were also not different between $\mathrm{HG}$ and nonHG controls $(P>0.10$, Table 3$)$.

\section{Cardiomyocyte sarcomere dynamics}

Representative cardiomyocyte sarcomere dynamics are illustrated in Figures 4A-D. Cardiomyocyte sarcomere shortening at $2 \mathrm{~Hz}$ (Figure $4 \mathrm{~A}$ and $4 \mathrm{~B}$ ) was greater in the HG $(6.46 \pm 0.28 \%)$ compared to nonHG controls $(5.48 \pm 0.28 \%, P<0.05$ ), but not at $6 \mathrm{~Hz}$ (Figures $4 \mathrm{C}$ and 4D). Diastolic sarcomere length at all pacing frequencies was shorter in the HG $(1.736 \pm 0.010 \mu \mathrm{m}$ at $2 \mathrm{~Hz})$ compared to nonHG controls $(1.770 \pm 0.007 \mu \mathrm{m}$ at $2 \mathrm{~Hz}$, $P<0.05)$. In both groups, diastolic sarcomere length shortened as pacing frequency increased, i.e., there was a lack of full relaxation with increasing pacing frequency. The HG group displayed a greater lack of full relaxation with pacing frequency compared to nonHG controls. 


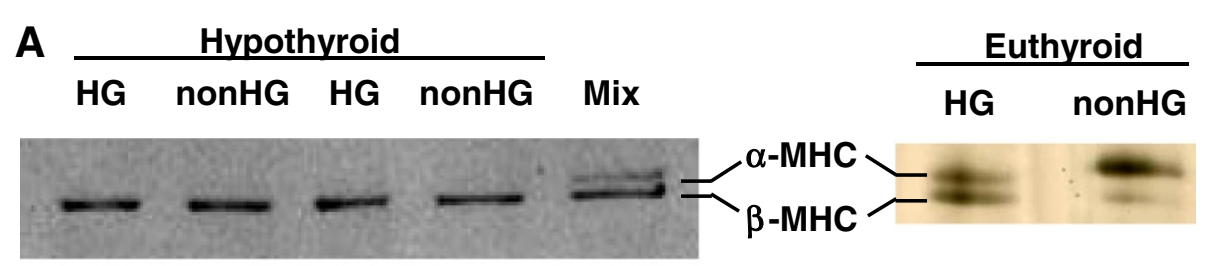

B

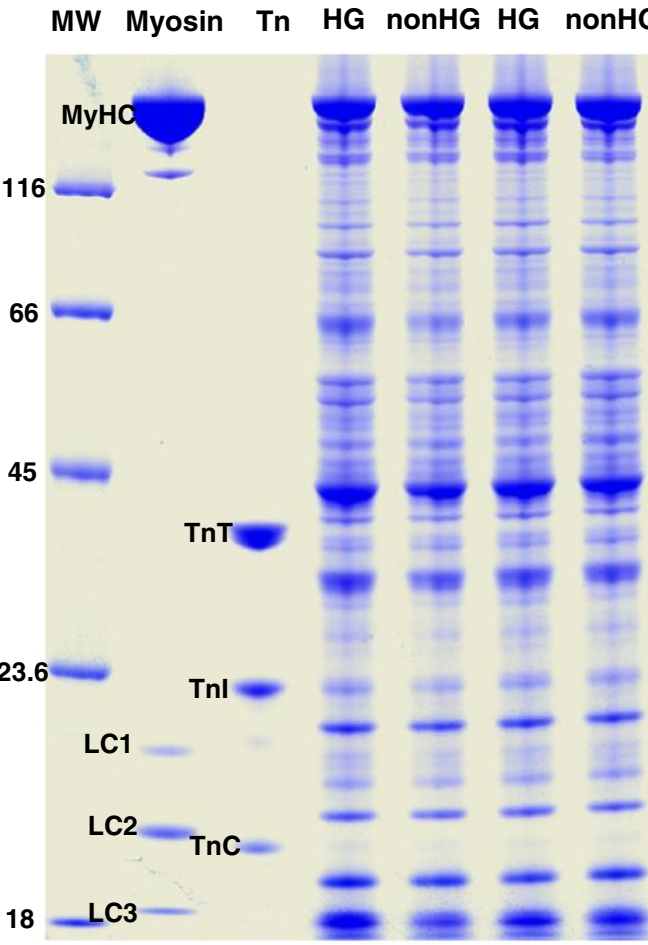

C Phospho-stain

HG nonHG HG nonHG

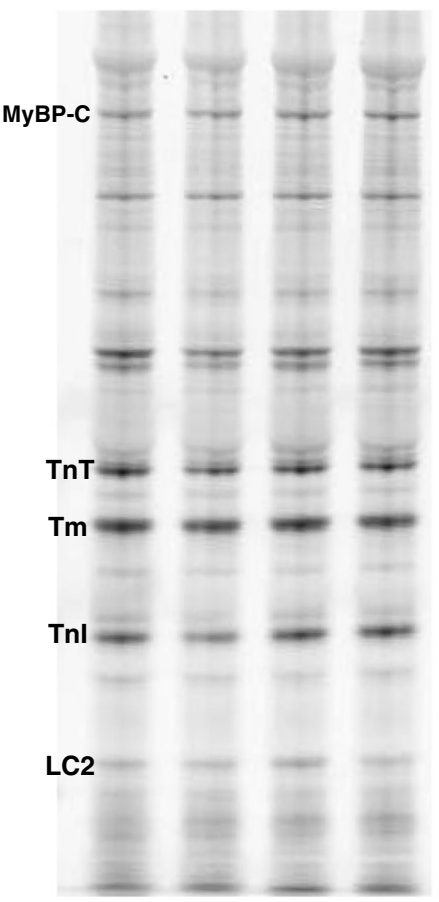

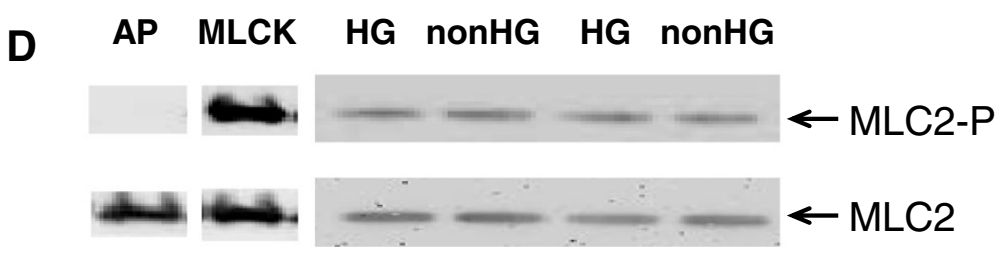

Figure 1 Myosin isoforms and myofibrillar protein phosphorylation. A. Gel electrophoresis stained with Coomassie-Blue demonstrate 100\% $\beta-\mathrm{MyHC}$ content in both $\mathrm{HG}$ and nonHG groups due to hypothyroidism. In euthyroid rats, HG results in a significant upregulation of cardiac $\beta-\mathrm{MyHC}$ compared to the a-MyHC predominately expressed in the nonHG rat heart. B and $\mathbf{C}$. Coomassie-blue and phospho-stain by Pro-Q Diamond indicated similar phosphorylation profiles of myofibrillar proteins in HG and nonHG. D. Western blots of phosphorylated MLC2 (MLC2-P) and total MLC content demonstrated similar degrees of phosphorylation in HG and nonHG controls. Additional lanes indicating alkaline phosphatase (AP) treatment to dephosphorylate MLC2 and myosin light chain kinase (MLCK) treatment to phosphorylate MLC2 provided negative and positive controls for MLC2 phosphorylation. Myosin = chicken skeletal myosin standard, Tn = bovine cardiac troponin standard, MyBP-C = myosin binding protein- $\mathrm{C}, \mathrm{Tm}=$ tropomyosin, $\mathrm{LC}=$ myosin light chain.

Exposure to extracellular $\mathrm{Zn}^{2+}$ reduced sarcomere shortening in both HG and nonHG. Extracellular $\mathrm{Zn}^{2+}$ enhanced diastolic sarcomere length significantly in the HG, particularly as pacing frequency increased, but did not significantly affect diastolic sarcomere length in the nonHG. Quantitative analyses regarding the sensitivity of contraction-relaxation function to $\mathrm{HG}$, pacing frequency and $\mathrm{Zn}^{2+}$ are presented below.

\section{Contraction function}

The variables used here to represent cardiomyocyte contractile function were peak sarcomere shortening and 
Table 2 Characteristics of myofilament force production in the skinned strip and of native thin filament (NTF) velocity in the myosin motility assay

\begin{tabular}{lll}
\hline & HG (n=6) & nonHG (6) \\
\hline $\mathrm{T}_{\min }\left(\mathrm{mN} / \mathrm{mm}^{2}\right)$ & $4.24 \pm 0.33$ & $4.87 \pm 0.18$ \\
\hline $\mathrm{T}_{\max }\left(\mathrm{mN} / \mathrm{mm}^{2}\right)$ & $15.8 \pm 1.4$ & $16.9 \pm 1.7$ \\
\hline $\mathrm{T}_{\text {dev }}\left(\mathrm{mN} / \mathrm{mm}^{2}\right)$ & $11.6 \pm 1.6$ & $12.1 \pm 1.8$ \\
\hline $\mathrm{pCa_{50 }}$ & $5.88 \pm 0.02$ & $5.89 \pm 0.02$ \\
\hline $\mathrm{n}_{\text {Hill }}$ & $3.41 \pm 0.38$ & $3.06 \pm 0.16$ \\
\hline & $(\mathrm{n}=3)$ & $(3)$ \\
\hline $\mathrm{V}_{\mathrm{Ca}, \mathrm{NTF}}(\mu \mathrm{m} / \mathrm{s})$ & $4.52 \pm 0.30$ & $4.62 \pm 0.29$ \\
\hline $\mathrm{pCa}_{50, \mathrm{NTF}}$ & $6.35 \pm 0.07$ & $6.32 \pm 0.06$ \\
\hline $\mathrm{n}_{\text {Hill, NTF }}$ & $1.36 \pm 0.22$ & $1.39 \pm 0.23$ \\
\hline
\end{tabular}

$\mathrm{T}_{\min }=$ minimum tensile stress, $\mathrm{T}_{\text {dev }}=$ developed tensile stress, $\mathrm{pCa}_{50}=\mathrm{pCa}$ at $50 \%$ calcium activation, $\mathrm{n}_{\mathrm{H}} \mathrm{ill}=$ Hill coefficient, $\mathrm{V}_{\mathrm{Ca} \text {, NTF }}=$ calcium-dependent NTF velocity.

maximum shortening velocity. Without $\mathrm{Zn}^{2+}$ exposure, cardiomyocyte peak shortening and maximum shortening velocity were statistically enhanced in HG compared to nonHG at 2 and $4 \mathrm{~Hz}$ pacing frequency, but not at $6 \mathrm{~Hz}$ (Figure 5A). Contractile function was reduced with increasing pacing frequency indicated by significant 'freq' main effects $(P<0.001$ in Table 4$)$. There were also significant 'HG $\times$ freq' interactions for peak shortening and maximum shortening velocity $(P<0.01$ in Table 4$)$ suggesting that the HG group was more susceptible to the reduction in contractile function with increasing pacing frequency. Exposure to extracellular $\mathrm{Zn}^{2+}$ reduced peak shortening and maximum shortening velocity (note significant 'zinc main effect' $P<0.001$ for these variables in Table 4) in both groups and subdued any differences between HG and nonHG controls (Figure 5A).

\section{Relaxation function}

The variables used here to represent cardiomyocyte relaxation function were maximum relengthening velocity, times to $50 \%$ relengthening, and diastolic sarcomere length. Without $\mathrm{Zn}^{2+}$ exposure, maximum relengthening velocity was significantly enhanced in the $\mathrm{HG}$ at 2 and $4 \mathrm{~Hz}$, but not at $6 \mathrm{~Hz}$ (Figure 5C). Maximum relengthening velocity was consistently enhanced with pacing frequency in the nonHG controls (Figure 5C), but not as much in the HG group (note significant freq main effect $P<0.001$ and HG $\times$ freq interaction $P=0.011$ in Table 5). These latter results indicate a reduced relaxationfrequency response due to HG. During $\mathrm{Zn}^{2+}$ exposure, maximum relengthening velocity remained significantly enhanced in the HG group compared to nonHG controls at 2 and $4 \mathrm{~Hz}$ (Figure 5C).

Time to $50 \%$ relengthening (Figure 5D) was not different between HG and nonHG unless cardiomyocytes were exposed to $\mathrm{Zn}^{2+}$. Specifically, during $\mathrm{Zn}^{2+}$ exposure, time to $50 \%$ relaxation was significantly shorter in the HG compared to nonHG at 2 and $4 \mathrm{~Hz}$, but not $6 \mathrm{~Hz}$ (Figure 5D). A similar effect, although not statistically significant $(P<0.15)$, was observed for time to $10 \%$ relengthening (not shown) and time to peak (Figure 5B).

Diastolic sarcomere length was significantly shorter in the HG compared to nonHG at all pacing frequencies both without and during $\mathrm{Zn}^{2+}$ exposure (Figure 5E). Diastolic sarcomere length shortened with increasing pacing frequency in both HG and nonHG (note 'freq' main

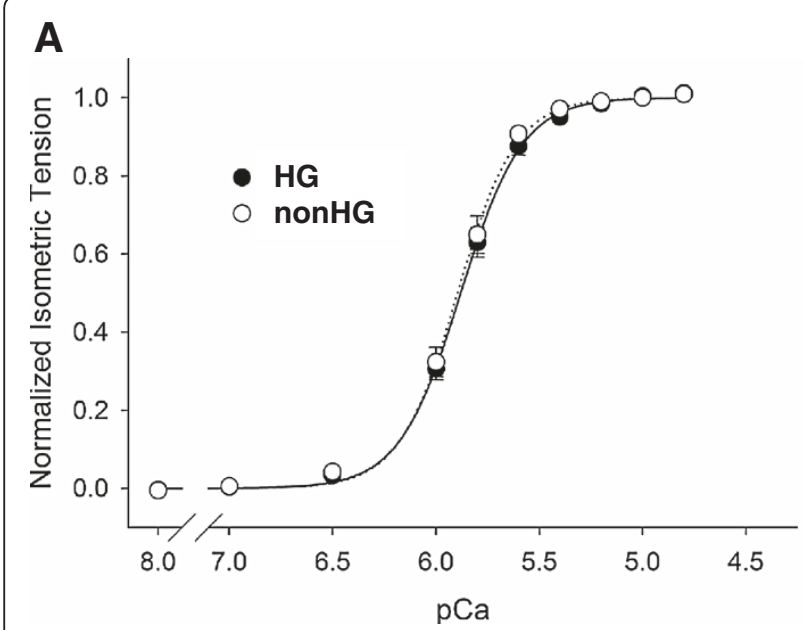

B

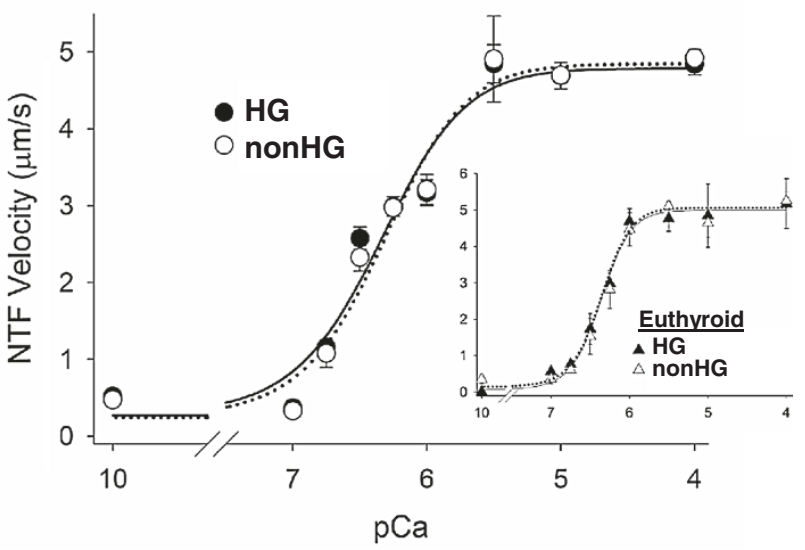

Figure 2 Thin filament characteristics and myofilament performance. A. Normalized isometric tension-calcium relationships of HG and nonHG controls were not different from each other, indicating similar thin filament sensitivities to calcium activation. B. Native thin filament (NTF) velocity-calcium relationships detected using the myosin motility assay were also similar between HG and nonHG demonstrating similar calcium sensitivity and myosin-actin MgATPase activity. Inset illustrates that HG did not affect NTF function in euthyroid rats not PTU-treated. 

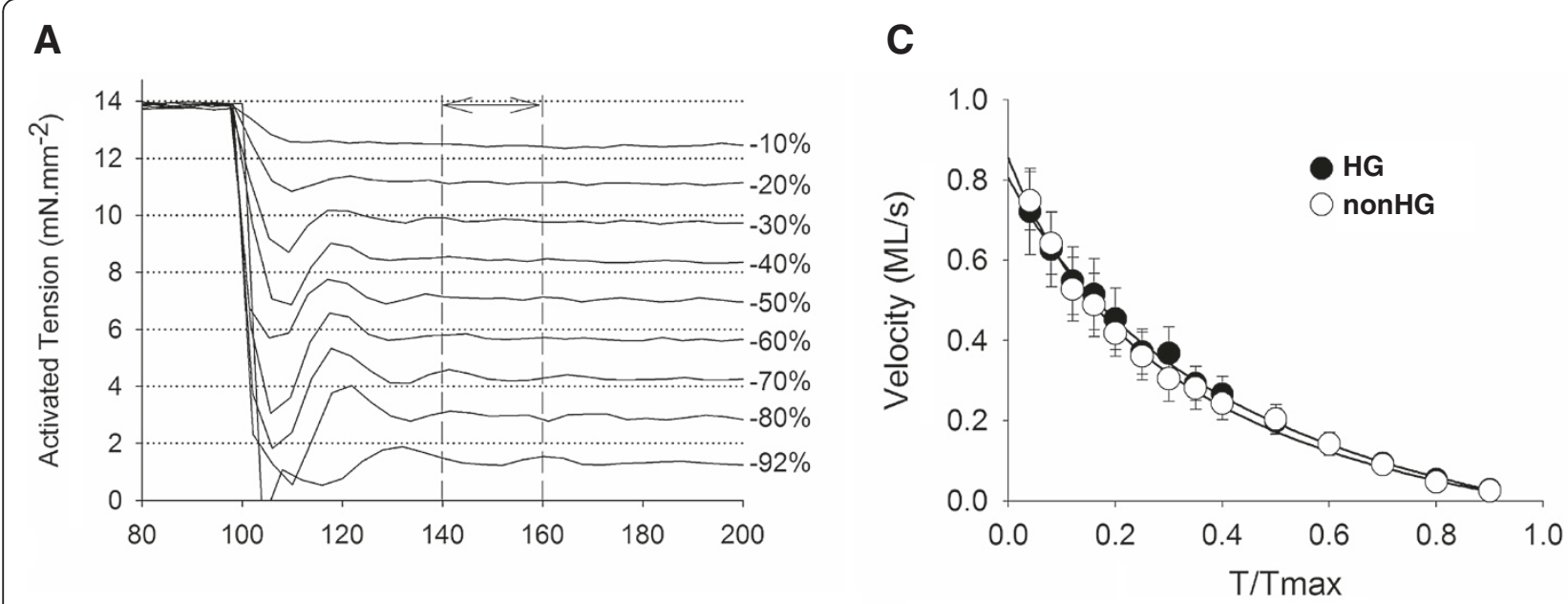

B
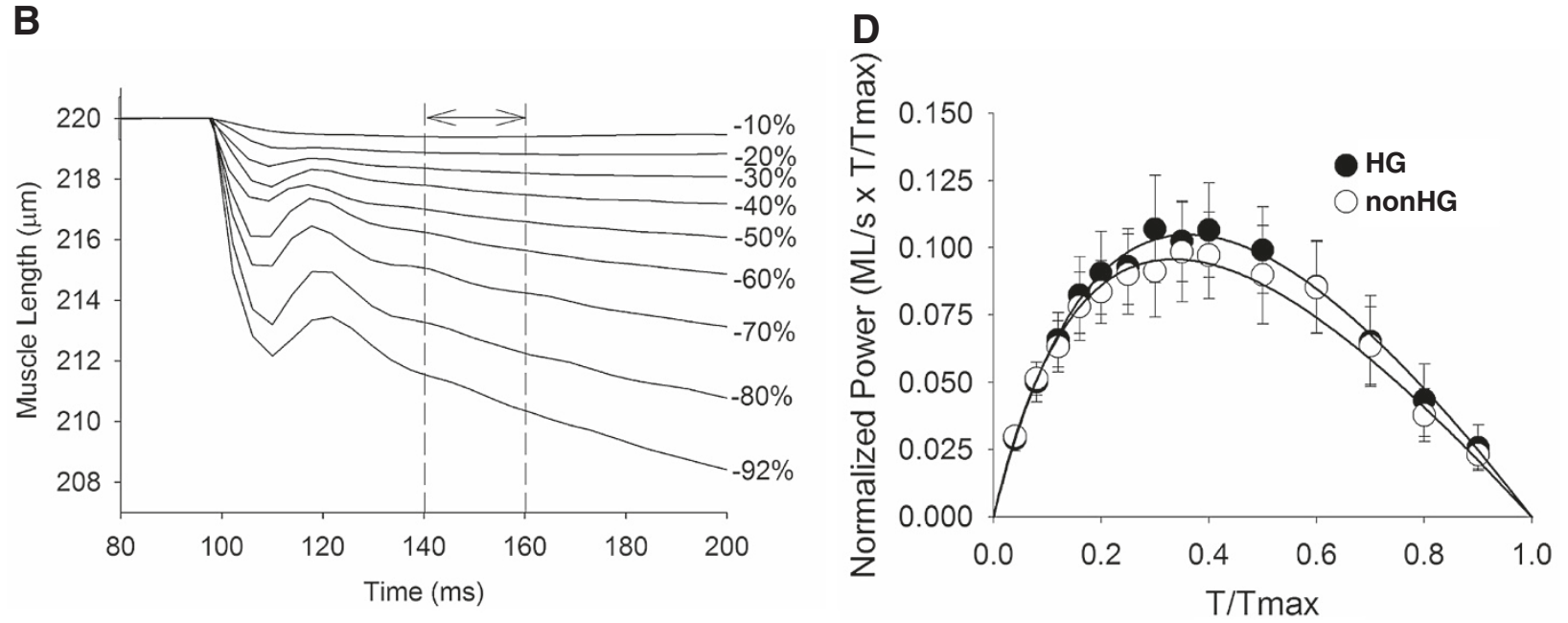

Figure 3 Example of force-clamp technique and results of tension-velocity and tension-power relationships. A. The force clamp technique relies upon using the force signal as feedback to the muscle length so that a preset force is achieved. The preset force varies from $10-96 \%$ and several examples are shown here. B. The resulting length change indicates velocity of contraction at the preset force. Velocity was calculated between 40-60 ms after the change in load. C-D. Tension-velocity and tension-power relationships were similar in HG and nonHG controls.

Table 3 Characteristics of force-velocity relationships in skinned strips

\begin{tabular}{lcc}
\hline $\mathrm{a} / \mathrm{T}_{\max }($ no units $)$ & HG (n=6) & nonHG (6) \\
\hline $\mathrm{b}\left(10^{-3} \mathrm{ML} / \mathrm{s}\right)$ & $0.501 \pm 0.086$ & $0.392 \pm 0.102$ \\
\hline $\mathrm{V}_{\max }\left(10^{-3} \mathrm{ML} / \mathrm{s}\right)$ & $414 \pm 104$ & $347 \pm 95$ \\
\hline $\mathrm{V}_{\text {opt }}\left(10^{-3} \mathrm{ML} / \mathrm{s}\right)$ & $817 \pm 125$ & $899 \pm 85$ \\
\hline $\mathrm{T}_{\text {opt }} / \mathrm{T}_{\max }(\%)$ & $292 \pm 45$ & $291 \pm 35$ \\
\hline $\mathrm{P}_{\max }\left(10^{-3} \mathrm{ML} / \mathrm{s} \times \mathrm{T} / \mathrm{T}_{\max }\right)$ & $35.8 \pm 1.5$ & $32.5 \pm 2.8$ \\
\hline
\end{tabular}

$\mathrm{a} / \mathrm{T}_{\max }=$ curvature index, $\mathrm{b}=$ velocity index, $\mathrm{V}_{\max }=$ extrapolated maximum unloaded velocity, $\mathrm{V}_{\mathrm{opt}}=$ velocity at maximum power, $\mathrm{T}_{\mathrm{opt}} / \mathrm{T}_{\max }=$ relative tension at maximum power, $\mathrm{P}_{\max }=$ maximum normalized power. effect $P<0.001$ in Table 4 ), but significantly more so in the HG compared to nonHG (indicated by $\mathrm{HG} \times$ freq interaction $P=0.005$ in Table 4).

As noted in Figure 5E, the reduction in diastolic sarcomere length with pacing frequency in the HG group appeared more subtle during $\mathrm{Zn}^{2+}$ exposure. Indeed, there was a $H G \times$ freq $\times$ zinc interaction $P=0.037$ for diastolic sarcomere length, which indicated a different sensitivity to pacing frequency between the groups that was dependent upon $\mathrm{Zn}^{2+}$ exposure. This interaction can be visualized more easily in Figure 5F, where the change in diastolic sarcomere length from that at $2 \mathrm{~Hz}$ is illustrated. As seen in Figure 5F, diastolic sarcomere length was reduced with increasing pacing frequency in both groups and significantly more so in the HG 
A

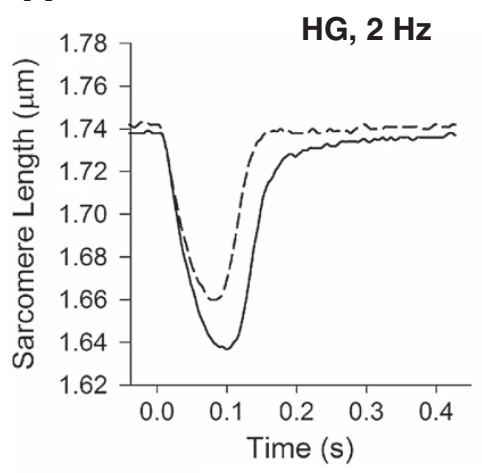

C
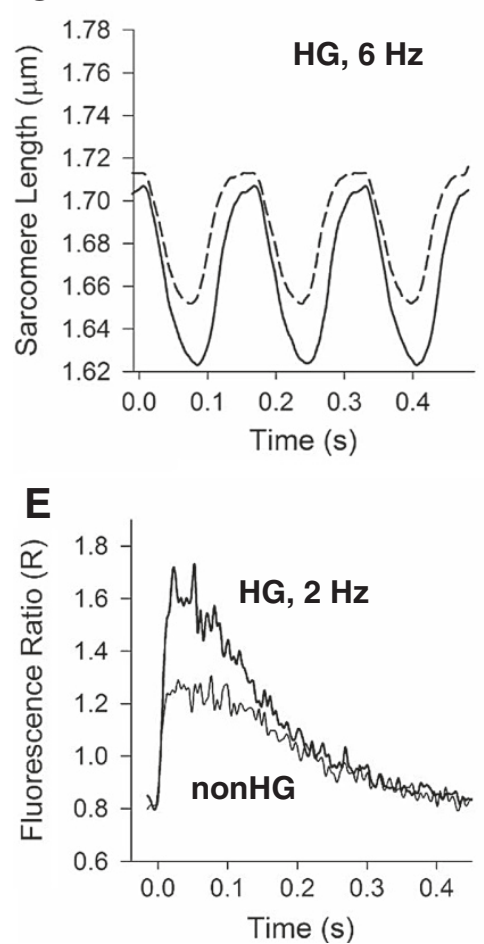

B

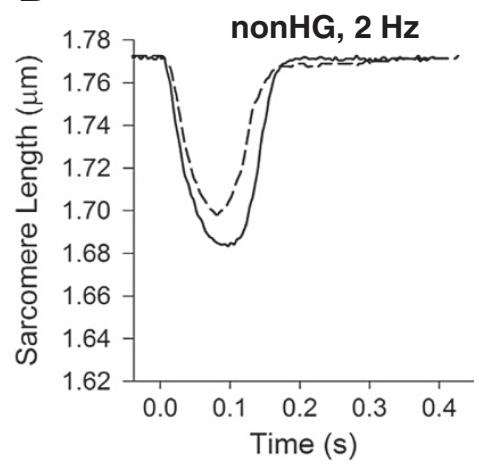

D

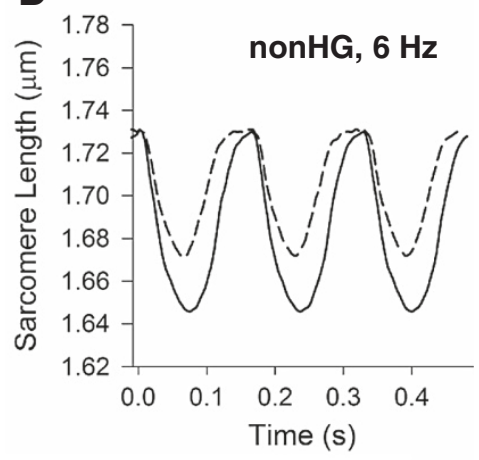

$\mathbf{F}$

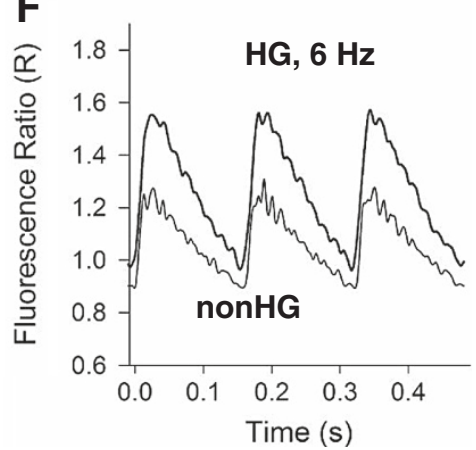

Figure 4 Representative cardiomyocyte sarcomere shortening-relengthening transients with (---) and without (-) $32 \mu \mathrm{M}$ extracellular $\mathrm{Zn}^{2+}$ and intracellular $\mathrm{Ca}^{2+}$ transients. A and $\mathbf{B}$. At $2 \mathrm{~Hz}$ cardiomyocyte shortening was greater in $\mathrm{HG}$ compared to nonHG. Diastolic sarcomere length was noticeably shorter in $\mathrm{HG}$ compared to nonHG at $2 \mathrm{~Hz}$. Extracellular $\mathrm{Zn}^{2+}$ reduced cardiomyocyte shortening in both $\mathrm{HG}$ and nonHG and led to longer diastolic sarcomere lengths in HG. C and $\mathbf{D}$. At $6 \mathrm{~Hz}$ extracellular $\mathrm{Zn}^{2+}$ reduced cardiomyocyte shortening in both $\mathrm{HG}$ and nonHG. Diastolic sarcomere length was still noticeably shorter in $\mathrm{HG}$ compared to nonHG, and exposure to $\mathrm{Zn}^{2+}$ led to longer diastolic sarcomere lengths in the HG group. $\mathbf{E}$ and $\mathbf{F}$. At 2 and $6 \mathrm{~Hz}$, fluorescence ratio transients of $\mathrm{HG}$ and nonHG cardiomyocytes were similar in temporal characteristics, but there was a greater area under Fura-2 fluorescence ratio transient in the $\mathrm{HG}$ at $2 \mathrm{~Hz}$ and a trend at $6 \mathrm{~Hz}$.

without $\mathrm{Zn}^{2+}$. The diastolic sarcomere length in the HG cardiomyocytes exposed to $\mathrm{Zn}^{2+}$ responded to pacing frequency similar to the nonHG group (Figure 5F).

In summary, relaxation function measured as maximum relengthening velocity, time to $50 \%$ relengthening and diastolic sarcomere length in the HG cardiomyocytes was more sensitive to the enhancing effects of extracellular $\mathrm{Zn}^{2+}$ compared to that in nonHG controls.

\section{Cardiomyocyte calcium dynamics}

Figures $4 \mathrm{E}$ and $4 \mathrm{~F}$ illustrate representative fluorescence ratio transients that reflect calcium dynamics in the cardiomyocytes of the HG and nonHG groups not exposed to $\mathrm{Zn}^{2+}$. Indices of systolic and diastolic performance are presented in Figure 6. The developed peak fluorescence ratio (R), i.e., peak minus diastolic $R$ (Figure 6A), was not statistically different between HG and nonHG, although we detected a trend for higher developed peak $\mathrm{R}$ 

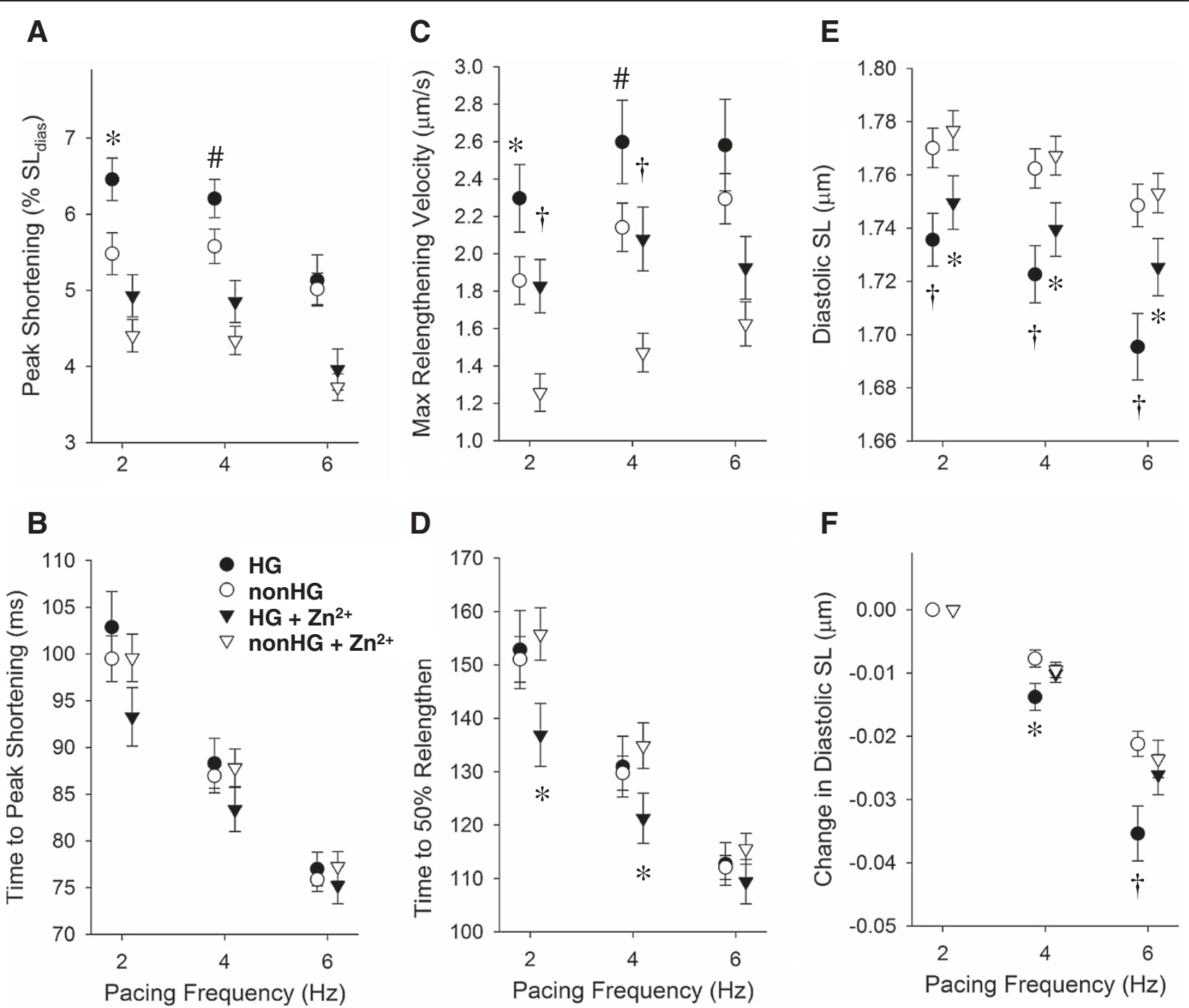

Figure 5 Parameters of cardiomyocyte sarcomere dynamics. A. Peak cardiomyocyte shortening was greater in $\mathrm{HG}$ compared to nonHG at 2 and $4 \mathrm{~Hz}$, but not at $6 \mathrm{~Hz}$. Exposure to $32 \mu \mathrm{M}\left[\mathrm{Zn}^{2+}\right]_{\text {ex }}$ reduced peak shortening in both groups and abolished differences in peak shortening between the groups. B. Time to peak shortening was not different between $\mathrm{HG}$ and nonHG and not affected by zinc exposure. $\mathbf{C}$. Both with and without $\left[\mathrm{Zn}^{2+}\right]_{\mathrm{ex}}$, maximum velocity of relengthening was greater in $\mathrm{HG}$ compared to nonHG at 2 and $4 \mathrm{~Hz}$, but not at $6 \mathrm{~Hz}$. Maximum velocity of relengthening in the nonHG group was enhanced with pacing frequency, but not as much in the HG group. D. Time to 50\% relengthening was enhanced by $32 \mu \mathrm{M}\left[\mathrm{Zn}^{2+}\right]_{e x}$ in the HG group only. E. Diastolic sarcomere length was shorter in HG compared to nonHG and shortened in both groups by increasing pacing frequency. $\mathbf{F}$. The change in diastolic sarcomere length with pacing frequency was greatest in $\mathrm{HG}$ cardiomyocytes not exposed to $\left[\mathrm{Zn}^{2+}\right]_{\text {ex }}$. Exposure to $32 \mu \mathrm{M}\left[\mathrm{Zn}^{2+}\right]_{\mathrm{ex}}$ in the $\mathrm{HG}$ cardiomyocytes recovered a normal response of diastolic sarcomere length to pacing frequency. $\# P<0.1,{ }^{*} P<0.05,+P<0.01 ; \mathrm{n}=8$ in each group.

at $6 \mathrm{~Hz}$. Time to peak R, exponential time constant for $\mathrm{R}$ decay, time to $50 \% \mathrm{R}$ decay and diastolic $\mathrm{R}$ were not different between HG and nonHG at any pacing frequency (Figures 6B-6E). Contrary to the higher SERCA2a expression and $\mathrm{SR} \mathrm{Ca}^{2+}$ reuptake rate reported for rats with type $2 \mathrm{DM}$ [41], we did not detect a greater SR $\mathrm{Ca}^{2+}$ reuptake rate in the HG cardiomyocytes. However, the area under the $\mathrm{R}$ transient, not including the area under diastolic $\mathrm{R}$, was greater in the HG compared to nonHG at all pacing frequencies (Figure 6F and Table 5).
These data would suggest that there was greater total cytosolic calcium over each cardiac cycle in the HG compared to nonHG in the absence of $\mathrm{Zn}^{2+}$ exposure. A greater total cytosolic calcium in the HG could explain in part the enhanced contraction function in the HG at the $2 \mathrm{~Hz}$ and $4 \mathrm{~Hz}$ pacing frequencies.

\section{Other post-translational modifications}

We examined several post-translational modifications implicated as significant modifiers of cardiomyocyte 
Table 4 Results of repeated measures ANOVA of cardiomyocyte shortening-relengthening characteristics

\begin{tabular}{|c|c|c|c|c|c|c|c|}
\hline Variable & HG & freq & HGXfreq & zinc & HGXzinc & freq $\times$ zinc & HGXfreq $\times$ zinc \\
\hline Peak Shortening (\%) & $0.013^{*}$ & $<0.001 \dagger$ & $0.008+$ & $<0.001 \dagger$ & 0.941 & 0.619 & 0.424 \\
\hline Peak Shortening $(\mu \mathrm{m})$ & $0.043^{*}$ & $<0.001 \dagger$ & $0.008+$ & $<0.001 \dagger$ & 0.992 & 0.698 & 0.374 \\
\hline Max Shortening dSL/dt $(\mu \mathrm{m} / \mathrm{s})$ & $0.028^{*}$ & $<0.001 \dagger$ & $0.016^{*}$ & $<0.001 \dagger$ & 0.922 & 0.624 & 0.582 \\
\hline Max Lengthening dSL/dt $(\mu \mathrm{m} / \mathrm{s})$ & $0.002^{*}$ & $<0.001 \dagger$ & $0.011^{*}$ & $<0.001 \dagger$ & 0.833 & 0.121 & 0.827 \\
\hline Time to Peak (ms) & 0.712 & $<0.001+$ & 0.295 & 0.354 & 0.158 & 0.153 & 0.674 \\
\hline Time to $10 \%$ return (ms) & 0.505 & $<0.001 \dagger$ & $0.082 \#$ & 0.294 & 0.215 & $0.094 \#$ & 0.706 \\
\hline Time to 50\% return (ms) & 0.230 & $<0.001 \dagger$ & $<0.001 \dagger$ & 0.554 & 0.249 & 0.368 & 0.534 \\
\hline Diastolic SL $(\mu \mathrm{m})$ & $<0.001+$ & $<0.001 \dagger$ & $0.005+$ & 0.722 & 0.913 & 0.176 & $0.037^{*}$ \\
\hline
\end{tabular}

The table presents $P$-values for the main effects of HG, freq and zinc and for interactions of HGXfreq, $\mathrm{HG} \times z$ inc, freq $\times z i n c$ and $\mathrm{HG} \times$ freq $\times z$ inc. $\# P<0.10,{ }^{*} P<0.05$, $+P<0.01 ; \mathrm{n}=8$ in each group.

function in HG. We found RyR phosphorylation at S2808 was enhanced in $\mathrm{HG}$ compared to nonHG (Figures 7A and 7B) as has been reported previously and implicated as a contributor of increased SR $\mathrm{Ca}^{2+}$ leak in HG [15]. The elevated phosphorylation of RyR S-2808 may result from a moderately elevated adrenergic environment in the myocardium due to reduced reuptake of norepinephrine in sympathetic nerves [42].

O-linked N-Acetylglucosamine (O-GlcNAc), which is known to occur with complications in HG and DM [43], was highly variable in both HG and nonHG samples, but was not detected on the major myofilament proteins (Figure 7C). The protein most subject to O-GlcNAc had a molecular weight of $\sim 65 \mathrm{kDa}$, possibly one of the intermediate filament proteins synocoilin or desmin, but was not differently affected in HG and nonHG controls (Figure 7C).

Accumulation of advanced glycated end-products (AGE), implicated as a contributor to myocardial stiffness in HG [44], was detected using anti-pentosidine probe (Figure $8 \mathrm{~B}$ ). Neither the myofilament nor nonmyofilament fractions of the tissue homogenate demonstrated differential AGE accumulation due to HG.

Lysine acetylation, which has been implicated as a significant modifier of myosin and myofilament function [45], was not apparent in myosin or in any of the major myofilament proteins (Figure 8A). Our examination of

Table 5 Results of repeated measures ANOVA of cardiomyocyte calcium transient characteristics

\begin{tabular}{llll}
\hline Variable & HG & freq & HGXfreq \\
\hline Peak - Diastolic Ratio (R) & 0.107 & 0.250 & 0.828 \\
\hline Area of Ratio Transient (R.ms) & $0.079 \#$ & $\mathbf{< 0 . 0 0 1 \dagger}$ & 0.179 \\
\hline Time to Peak (ms) & 0.673 & $\mathbf{< 0 . 0 0 1 \dagger}$ & 0.941 \\
\hline Time to 50\% return (ms) & 0.111 & $\mathbf{< 0 . 0 0 1 \dagger}$ & 0.546 \\
\hline Exponential Time Constant (ms) & 0.514 & $\mathbf{< 0 . 0 0 1 \dagger}$ & 0.815 \\
\hline Diastolic Ratio (R) & 0.340 & 0.100 & 0.532 \\
\hline
\end{tabular}

The table presents $P$-values for the main effects of $H G$ and freq and for interactions of $\mathrm{HG} \times$ freq. $\# P<0.10,{ }^{*} P<0.05,+P<0.01 ; \mathrm{n}=8$ in each group. myofilament composition in terms of myosin isoform and of commonly assessed post-translational modifications of myofilament proteins did not result in our finding any significant differences between the $\mathrm{HG}$ and nonHG hypothyroid rats.

\section{Cardiac element content}

HG in the hypothyroid rat led to elevations in iron and sulfur per cardiac tissue wet weight (Table 6), while there was no effect on the other elements. In particular, myocardial calcium and zinc concentrations were similar between the HG and nonHG hypothyroid rats. Euthryroid rats, however, responded to HG with an elevation in calcium, potassium, sodium and sulfur and a reduction in copper and iron (Table 6). Interestingly, neither the hypothyroid nor euthyroid rats demonstrated changes in magnesium, phosphorus or zinc content due to HG, and both hypothryroid and euthyroid rats demonstrated a 20-25\% increase in sulfur with HG.

\section{Gene expression}

Zinc binds to the metal responsive element (MRE) on the promoter region of select genes and thereby signals activity of metal response element-binding transcription factor-1 (MTF-1) and the subsequent transcription of several genes related to zinc homeostasis and protection against oxidative stress: metallothionein-1 (MT1a), $\gamma$ glutamylcysteine synthase heavy chain $(\gamma$-GCSh) and zinc transporters-1 and -2 (ZnT1, ZnT2) [46-48]. Given the previous findings of an upregulation of MT1a in mouse hearts after STZ injection [19], we expected a similar upregulation of MTF-1 dependent genes in the hearts of our euthyroid HG rats. (We did not examine gene expression in the hypothyroid rats due to lack of tissue.) Instead we found that HG due to STZ injection led to a significant reduction in MT1a and ZnT2 expression, similar to a downregulation of MT1a in cardiac tissue of diabetic mouse embryos [49] (Table 6). Our data suggest that MTF-1 activity is reduced with HG, reflected in MT1a and ZnT2 downregulation, despite a 


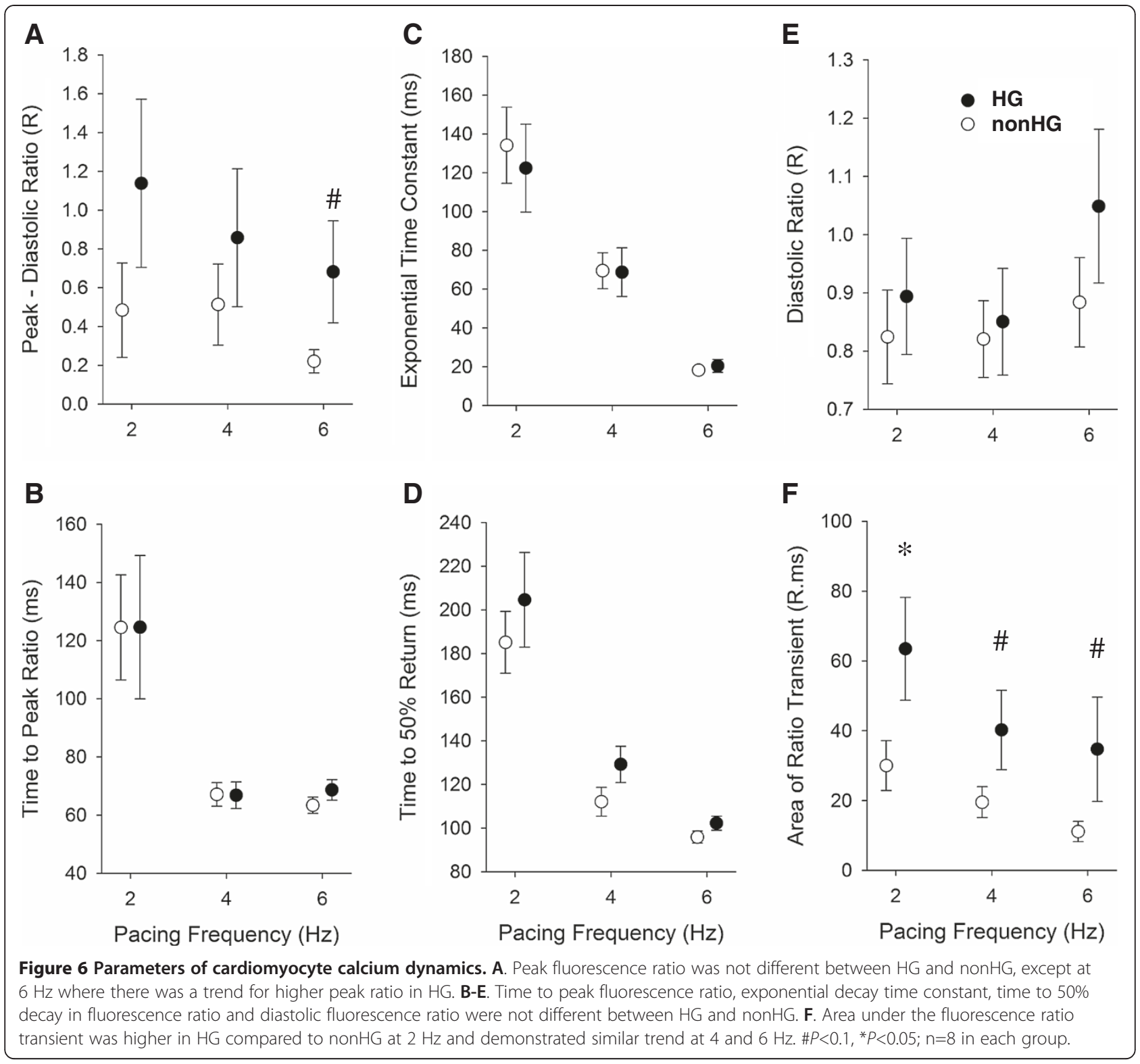

normal level of Zn content. We also report an upregulation of $\gamma$-GCSh, which is consistent with the increased glutathione content in the hearts of diabetic mouse embryos [49]. The regulation of $\gamma$-GCSh in this case is likely driven by some other transcription factor other than MTF-1 [50], due in part to the promoter of the $\gamma$-GCSh gene bearing only a single MRE and may not be as dependent upon MTF-1 activity as MT and ZnT genes bearing 3-6 MRE's [50].

\section{Discussion}

We report here the effects of HG induced by $\beta$-islet necrosis on cardiomyocyte function in hypothyroid rats. Hypothyroidism was induced in these rats to ensure the expression of $100 \% \beta-\mathrm{MyHC}$ in the ventricles of both disease and control groups. We found no significant effects of HG on echocardiographic measures of cardiac function or on myofilament performance in the context of hypothyroidism. These findings support the arguments raised by Dillmann [27], Davidoff et al. [5,26] and Rundell et al. [29] that modifications in myofilament function due to HG in rodents are primarily if not exclusively through myosin isoform shifts secondary to associated hypothyroidism. With our unique animal model of HG, we were able to demonstrate the effects of HG on cardiomyocyte function independent of differential $\mathrm{MyHC}$ isoform expression and its associated effects on myofilament performance and yet with greater relevance to the human heart, which expresses predominately $\beta-\mathrm{MyHC}$. 
A

Ryanodine Receptor
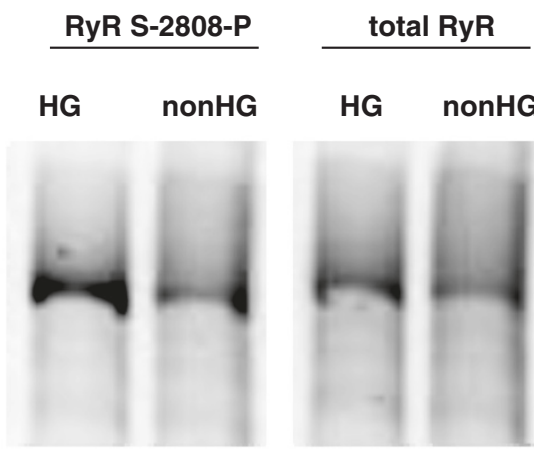

HG nonHG

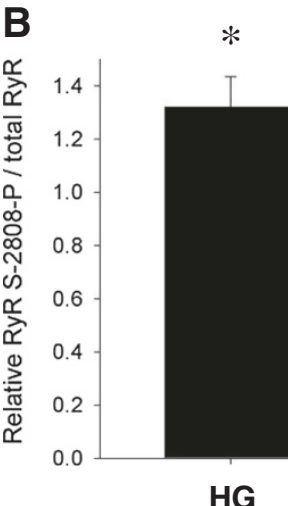

HG
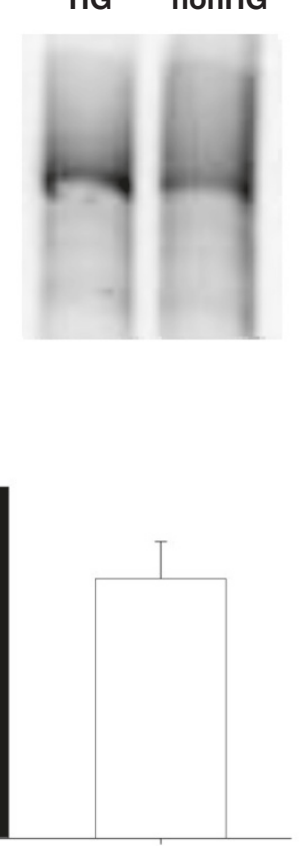

nonHG

C
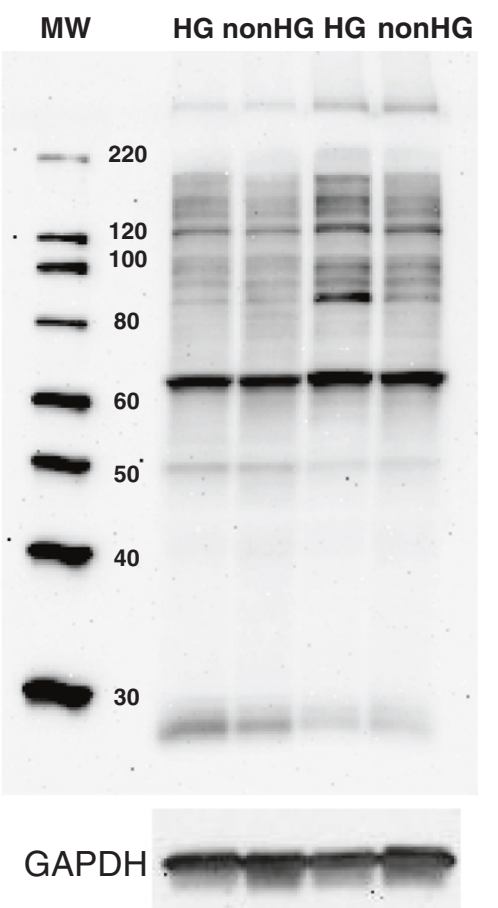

Figure 7 Post translational modifications due to HG. A and B. RyR phosphorylation at S-2808 normalized to total RyR content was significantly enhanced in $\mathrm{HG}$ compared to nonHG. C. O-linked N-Acetylglucosamine (O-GlcNAc) was not apparent in myofibrillar proteins except possibly an interfilament protein at $\sim 65 \mathrm{kDa}$, which was not differentially affected by $\mathrm{HG}$. MW $=$ molecular weight marker. ${ }^{*} P<0.05$; $\mathrm{n}=4$.

\section{Cardiomyocyte Sensitivity to $\mathrm{Zn}^{2+}$ in HG}

We found that extracellular $\mathrm{Zn}^{2+}$ enhanced relaxation function only in the cardiomyocytes of $\mathrm{HG}$ rats and not in the nonHG. Most notably, incomplete relaxation as pacing frequency increased was more prominent in $\mathrm{HG}$, and extracellular $\mathrm{Zn}^{2+}$ exposure to the $\mathrm{HG}$ cardiomyocytes regained a normal relaxation response to pacing frequency. This is a novel and important finding that highlights the detrimental effect of HG on cardiomyocyte $\mathrm{Ca}^{2+}$ regulation and its amelioration by $\mathrm{Zn}^{2+}$. These results are consistent with the idea that HG leads to a higher cardiomyocyte intracellular $\mathrm{Ca}^{2+}$ load leading to incomplete relaxation and also a higher sensitivity to the relaxing effects of extracellular $\mathrm{Zn}^{2+}$.

The molecular mechanisms, which underlie cardiomyocyte relaxation affected by extracellular $\mathrm{Zn}^{2+}$ exposure or intracellular $\mathrm{Zn}^{2+}$ accumulation, may be targets for the treatment of diastolic dysfunction in diabetic cardiomyopathy. Due to the protean effects of zinc on cellular functions an exhaustive study of zincs effects on cardiomyocyte contractile function is beyond the scope of our current investigation. Intracellular
$\mathrm{Zn}^{2+}$ is known to activate or deactivate a number of kinases and phosphatases, reviewed in Foster and Samman [51], as well as compete with $\mathrm{Ca}^{2+}$ for calcium regulatory proteins and channels [23,24]. Given the rapidity with which the extracellular $\mathrm{Zn}^{2+}$ exposure affected cardiomyocyte function and the recent findings that $\mathrm{Zn}^{2+}$ regulation appears to follow that of $\mathrm{Ca}^{2+}$ [25], we would hypothesize that the most immediate effects of $\mathrm{Zn}^{2+}$ on cardiomyocyte function involve a competitive effect on $\mathrm{Ca}^{2+}$ regulatory mechanisms. By reducing the inward $\mathrm{Ca}^{2+}$ current through the L-type channel [23,24], for example, extracellular $\mathrm{Zn}^{2+}$ exposure could lower the open probability of RyR and presumably also reduce SR $\mathrm{Ca}^{2+}$ leak through the RyR, which has been shown to be elevated in HG $[13,14]$. Our finding an elevated RyR phosphorylation at S-2808 in our HG rats is consistent with that reported by others [15] and suggests that the hypothyroid state did not diminish the effects of HG on RyR post-translational modifications and possibly also its function. It must be noted, however, that HG-dependent enhancement of RyR open probability may be independent of S-2808 phosphorylation [14]. 


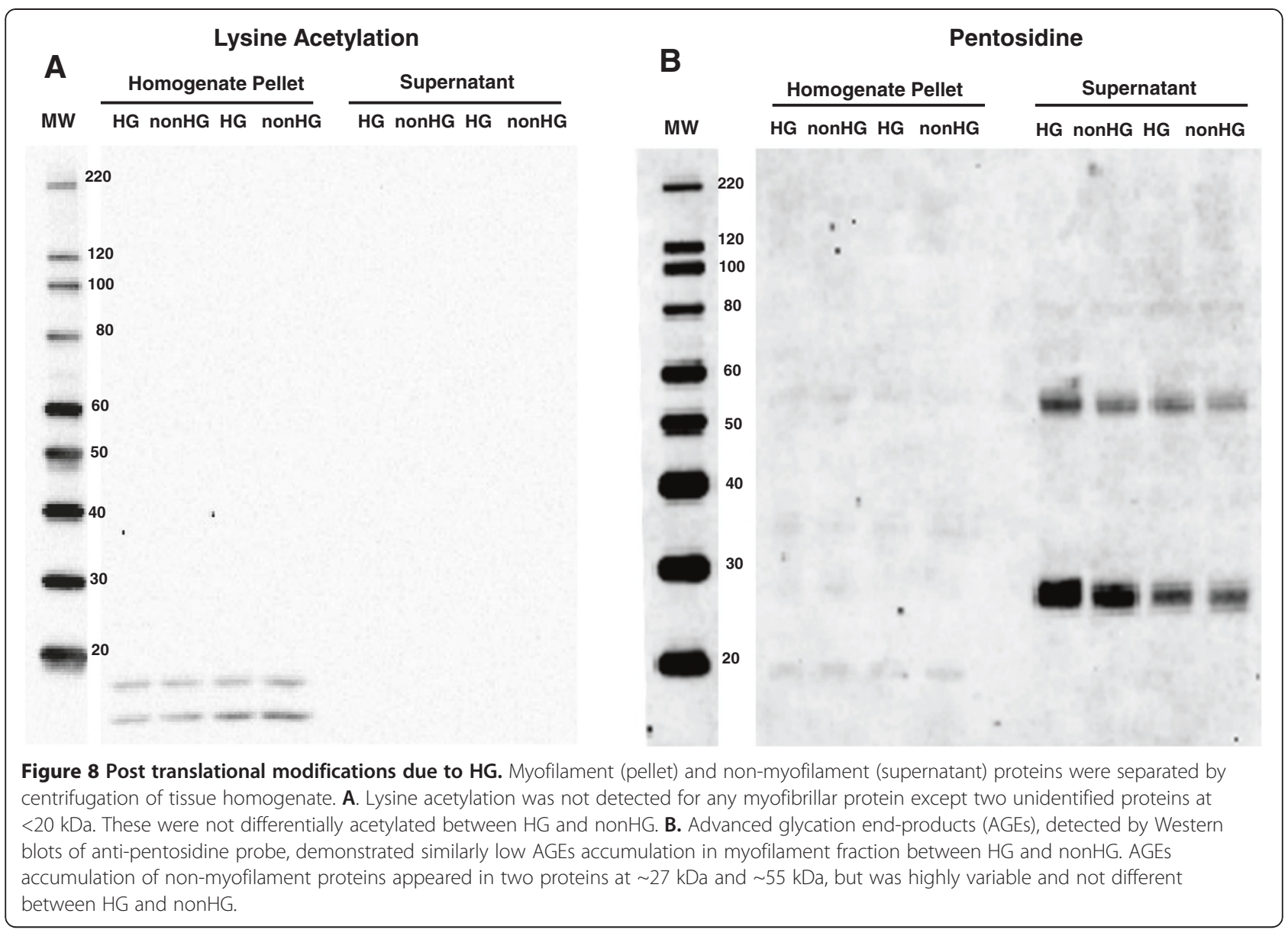

Table 6 Cardiac element content and select gene expression at 6 wks after injection of STZ (HG) or vehicle (nonHG) in hypothyroid rats fed PTU diet or in euthyroid rats fed standard rat chow

\begin{tabular}{lllll}
\hline & \multicolumn{2}{c}{ Hypothyroid } & \multicolumn{2}{c}{ Euthyroid } \\
\hline $\mathrm{Ca}$ & $\mathrm{HG}(\mathrm{n}=8)$ & $\mathrm{nonHG}(8)$ & $\mathrm{HG}(6)$ & nonHG (6) \\
\hline $\mathrm{Cu}$ & $401.2 \pm 6.0$ & $100.8 \pm 7.4$ & $284.4 \pm 44.3^{*}$ & $155.4 \pm 32.9$ \\
\hline $\mathrm{Fe}$ & $66.7 \pm 3.0^{*}$ & $58.7 \pm 1.9$ & $95.5 \pm 2.5+$ & $122.3 \pm 7.5$ \\
\hline $\mathrm{K}$ & $2316 \pm 148$ & $2053 \pm 85$ & $7369 \pm 793^{*}$ & $5052 \pm 566$ \\
\hline $\mathrm{Mg}$ & $186.8 \pm 8.9$ & $177.3 \pm 7.6$ & $275.1 \pm 13.6$ & $257.8 \pm 6.0$ \\
\hline $\mathrm{Na}$ & $1863 \pm 102$ & $1788 \pm 75$ & $2325 \pm 224 *$ & $1641 \pm 186$ \\
\hline $\mathrm{P}$ & $2158 \pm 105$ & $2012 \pm 81$ & $2726 \pm 86$ & $2711 \pm 24$ \\
\hline $\mathrm{S}$ & $2545 \pm 155 *$ & $2022 \pm 102$ & $3707 \pm 163^{*}$ & $3149 \pm 95$ \\
\hline $\mathrm{Zn}$ & $17.6 \pm 0.7$ & $17.7 \pm 0.8$ & $23.1 \pm 1.1$ & $22.2 \pm 0.3$ \\
\hline MT1a & - & - & $0.66 \pm 0.13 *$ & $1.00 \pm 0.05$ \\
\hline ZnT2 & - & - & $0.76 \pm 0.07 \#$ & $1.00 \pm 0.10$ \\
\hline Y-GCSh & - & - & $1.30 \pm 0.08 \dagger$ & $1.00 \pm 0.03$
\end{tabular}

Concentration given in ppm: $\mu \mathrm{g}$ of element per $\mathrm{g}$ wet weight of LV. Gene expression given in $\mathrm{RQ}=2^{-\Delta \Delta \mathrm{Ct}}$. normalized to HPRT expression and then to mean of nonHG. Differences between $\mathrm{HG}$ and nonHG controls reported at ${ }^{*} P<0.05,+P<0.01$.

\section{Cardiomyocyte $\mathrm{Ca}^{2+}$ regulation in HG}

HG in this model led to enhanced cardiomyocyte contraction function at lower than in vivo stimulation frequencies. These results suggest an elevated $\mathrm{SR} \mathrm{Ca}^{2+}$ load and release in the HG cardiomyocytes, consistent with the greater area under the Fura-2 fluorescence ratio transient we observed in the HG. We also found a significantly reduced diastolic sarcomere length in the HG. The elevated cardiomyocyte contraction function and reduced diastolic sarcomere length in the absence of any variation in myofilament calcium sensitivity collectively suggest elevated systolic and diastolic intracellular $\mathrm{Ca}^{2+}$ concentrations with HG. However, we were not able to detect an elevated diastolic $\mathrm{Ca}^{2+}$ concentration with HG.

Our measures of intracellular $\mathrm{Ca}^{2+}$ by Fura- 2 suggest that calcium regulation in the cardiomyocytes of the HG rat were altered to contribute to an elevated $\mathrm{SR} \mathrm{Ca}^{2+}$ load at relatively low pacing frequencies $(2-4 \mathrm{~Hz})$. In the current study, we did not measure intracellular $\mathrm{Ca}^{2+}$ during exposure to extracellular $\mathrm{Zn}^{2+}$, because Fura-2 is sensitive to both physiological $\mathrm{Zn}^{2+}$ and $\mathrm{Ca}^{2+}$ [23]. To our knowledge, there is no other $\mathrm{Ca}^{2+}$ dye sensitive to $\mathrm{Ca}^{2+}$ with a $K_{d}<1 \mu \mathrm{M}$ (which would be necessary to detect 
intracellular $\mathrm{Ca}^{2+}$ dynamics), that is also insensitive to physiological intracellular $\mathrm{Zn}^{2+}$. Based on the response of sarcomere dynamics, we suspect that cardiomyocyte $\mathrm{Ca}^{2+}$ load, peak systolic $\mathrm{Ca}^{2+}$ and diastolic $\mathrm{Ca}^{2+}$ concentrations would be reduced as intracellular $\mathrm{Zn}^{2+}$ accumulated.

\section{Cardiac elemental content and gene expression}

We are aware of only two other studies of the effects of $\beta$-islet necrosis on cardiac elemental content. LV contents of calcium and copper were reduced in the euthyroid rat after 6-8 wks HG due to STZ [52], and zinc is reduced in a mouse model after 6 wks HG due to alloxan [53]. Our findings in the euthyroid rat indicate significant changes in the regulation of several elements after HG induction by STZ; however, we would not be able to tell if these changes are due to the primary effects of $\mathrm{HG}$ or due to secondary effects of some other syndrome accompanying HG. Interestingly, gene expression levels for MT1a and ZnT2 were reduced in the euthyroid HG rats despite the normal levels of myocardial zinc. We speculate that HG nevertheless depresses activity of MTF-1, which is the common transcription factor to activate $\mathrm{MT}$ and $\mathrm{ZnT} 2$ [46-48]. We propose that this mechanism is reflected in the elevated sulfur content, which suggests a higher density of zinc-buffering sulfur-rich proteins like glutathione [49] and subsequently reduced zinc availability to signal MTF-1 activity [54].

In the hypothyroid rats, LV contents of iron and sulfur are elevated with 6 wks of HG and there were no other changes in elemental contents. Therefore, there was no zinc deficiency with HG that could account for the higher $\mathrm{Zn}^{2+}$ sensitivity in the HG cardiomyocytes. However, we speculate that an elevation in sulfur-rich proteins in the HG hearts reduces the zinc available to activate or deactivate kinases and phosphatases that affect phosphorylation status of calcium regulatory proteins such as RyR.

\section{Conclusions}

We demonstrate here a unique and valuable animal model, the hypothyroid rat, which eliminated the complicating factors of disparate thyroid status, myofilament function, myosin isoform composition and posttranslational modifications due to HG or DM in euthyroid animals. This model may prove particularly useful in further studies of the effects of HG and DM on cardiac cellular and molecular functions.

This report provides evidence supporting zinc administration as a possible long term management regimen for incomplete relaxation and diastolic dysfunction associated with diabetic cardiomyopathy. Human patients with type $2 \mathrm{DM}$ demonstrate an increased mortality due to coronary heart disease (CHD) and myocardial infarction inversely proportional to serum zinc levels [55]. Thus, elevation of extracellular zinc may reduce the risks of CHD with $\mathrm{DM}$, but also potentially enhanced diastolic function in these patients most at risk. The data presented here suggest that calcium regulatory mechanisms, particularly those responsible for cytosolic $\mathrm{Ca}^{2+}$ decline in diastole, are sensitive to $\mathrm{Zn}^{2+}$ exposure and more so sensitive in the diabetic heart despite normal total content of cardiac calcium and zinc. Further investigations into the $\mathrm{Zn}^{2+}$ sensitivity of calcium regulatory mechanisms responsible for relaxation, such as $\mathrm{Na}^{+}-\mathrm{Ca}^{2+}$ exchanger and SERCA2a, are warranted and currently underway.

\section{Competing interests}

The authors declare that they have no competing interests.

\section{Authors' contributions}

Experiments were conceived and designed by TY, YC, PV and BMP. Primary data were acquired by TY, YC, SMT, MS, SPB and ZC. Secondary analyses and interpretations were performed by TY, YC, MS, MML, PV and BMP. Manuscript and figures were drafted and proofed by TY, SMT, MML, PV and BMP. All authors read and approved the final manuscript.

\section{Acknowledgments}

This work was supported by NIH grants R01 HL086902 and R01 HL089944. We would like to thank Dr. Gregory Druschel for assistance with the ICP and Ms. Gabriela Mora for her technical expertise in the ICP laboratory at the Department of Geology, University of Vermont. The ICP instrument was provided by an NSF grant to Dr. Paul Bierman, EAR0132169.

\section{Author details}

'Department of Molecular Physiology and Biophysics, University of Vermont, 122 HSRF Beaumont Ave, Burlington VT 05405, USA. ²Department of Medicine, University of Vermont, Burlington VT 05405, USA.

Received: 28 August 2012 Accepted: 20 October 2012

Published: 2 November 2012

\section{References}

1. Regan TJ, Lyons MM, Ahmed SS, Levinson GE, Oldewurtel HA, Ahmad MR, Haider B: Evidence for cardiomyopathy in familial diabetes mellitus. J Clin Invest 1977, 60(4):884-899.

2. Diamant M, Lamb HJ, Groeneveld Y, Endert EL, Smit JW, Bax JJ, Romijn JA, de Roos A, Radder JK: Diastolic dysfunction is associated with altered myocardial metabolism in asymptomatic normotensive patients with well-controlled type 2 diabetes mellitus. J Am Coll Cardiol 2003, 42(2):328-335.

3. Scognamiglio R, Avogaro A, Negut C, Piccolotto R, Vigili De Kreutzenberg S, Tiengo A: Early myocardial dysfunction in the diabetic heart: current research and clinical applications. Am J Cardio/ 2004, 93(8A):17A-20A.

4. Fang ZY, Prins JB, Marwick TH: Diabetic cardiomyopathy: evidence, mechanisms, and therapeutic implications. Endocr Rev 2004, 25(4):543-567.

5. Davidoff AJ, Pinault FM, Rodgers RL: Ventricular relaxation of diabetic spontaneously hypertensive rat. Hypertension 1990, 15(6 Pt 1):643-651.

6. Boudina S, Abel ED: Diabetic cardiomyopathy revisited. Circulation 2007, 115(25):3213-3223.

7. Bugger $\mathrm{H}$, Abel ED: Mitochondria in the diabetic heart. Cardiovascular research 2010, 88(2):229-240.

8. Fein FS, Kornstein LB, Strobeck JE, Capasso JM, Sonnenblick EH: Altered myocardial mechanics in diabetic rats. Circ Res 1980, 47(6):922-933.

9. Zola BE, Miller B, Stiles GL, Rao PS, Sonnenblick EH, Fein FS: Heart rate control in diabetic rabbits: blunted response to isoproterenol. Am J Physiol 1988, 255(5 Pt 1):E636-641. 
10. Lacombe VA, Viatchenko-Karpinski S, Terentyev D, Sridhar A, Emani S, Bonagura JD, Feldman DS, Gyorke S, Carnes CA: Mechanisms of impaired calcium handling underlying subclinical diastolic dysfunction in diabetes. Am J Physiol Regul Integr Comp Physiol 2007, 293(5):R1787-1797.

11. Zhang L, Cannell MB, Phillips AR, Cooper GJ, Ward ML: Altered calcium homeostasis does not explain the contractile deficit of diabetic cardiomyopathy. Diabetes 2008, 57(8):2158-2166.

12. Suarez J, Scott B, Dillmann WH: Conditional increase in SERCA2a protein is able to reverse contractile dysfunction and abnormal calcium flux in established diabetic cardiomyopathy. Am J Physiol Regul Integr Comp Physiol 2008, 295(5):R1439-1445.

13. Shao CH, Rozanski GJ, Patel KP, Bidasee KR: Dyssynchronous (non-uniform) $\mathrm{Ca} 2+$ release in myocytes from streptozotocin-induced diabetic rats. Journal of molecular and cellular cardiology 2007, 42(1):234-246.

14. Tian C, Shao CH, Moore CJ, Kutty S, Walseth T, DeSouza C, Bidasee KR: Gain of function of cardiac ryanodine receptor in a rat model of type 1 diabetes. Cardiovascular research 2011, 91(2):300-309.

15. Yaras N, Ugur M, Ozdemir S, Gurdal H, Purali N, Lacampagne A, Vassort G, Turan B: Effects of diabetes on ryanodine receptor Ca release channel (RyR2) and Ca2+ homeostasis in rat heart. Diabetes 2005, 54(11):3082-3088.

16. Shen X, Zheng S, Thongboonkerd V, Xu M, Pierce WM Jr, Klein JB, Epstein PN: Cardiac mitochondrial damage and biogenesis in a chronic model of type 1 diabetes. Am J Physiol Endocrinol Metab 2004, 287(5):E896-905.

17. Wang J, Song Y, Elsherif L, Song Z, Zhou G, Prabhu SD, Saari JT, Cai L: Cardiac metallothionein induction plays the major role in the prevention of diabetic cardiomyopathy by zinc supplementation. Circulation 2006, 113(4):544-554.

18. Liang Q, Carlson EC, Donthi RV, Kralik PM, Shen X, Epstein PN: Overexpression of metallothionein reduces diabetic cardiomyopathy. Diabetes 2002, 51(1):174-181.

19. Song Y, Wang J, Li Y, Du Y, Arteel GE, Saari JT, Kang YJ, Cai L: Cardiac metallothionein synthesis in streptozotocin-induced diabetic mice, and its protection against diabetes-induced cardiac injury. Am J Pathol 2005, 167(1):17-26.

20. Wold LE, Ceylan-Isik AF, Fang CX, Yang X, Li SY, Sreejayan N, Privratsky JR, Ren J: Metallothionein alleviates cardiac dysfunction in streptozotocininduced diabetes: role of $\mathrm{Ca} 2+$ cycling proteins, NADPH oxidase, poly (ADP-Ribose) polymerase and myosin heavy chain isozyme. Free radical biology \& medicine 2006, 40(8):1419-1429.

21. Powell SR, Aiuto L, Hall D, Tortolani AJ: Zinc supplementation enhances the effectiveness of St. Thomas' Hospital No. 2 cardioplegic solution in an in vitro model of hypothermic cardiac arrest. J Thorac Cardiovasc Surg 1995, 110(6):1642-1648.

22. Powell SR, Nelson RL, Finnerty J, Alexander D, Pottanat G, Kooker K, Schiff RJ, Moyse J, Teichberg S, Tortolani AJ: Zinc-bis-histidinate preserves cardiac function in a porcine model of cardioplegic arrest. Ann Thorac Surg 1997, 64(1):73-80

23. Atar D, Backx PH, Appel MM, Gao WD, Marban E: Excitation-transcription coupling mediated by zinc influx through voltage-dependent calcium channels. J Biol Chem 1995, 270(6):2473-2477.

24. Turan B: Zinc-induced changes in ionic currents of cardiomyocytes. Biol Trace Elem Res 2003, 94(1):49-60.

25. Tuncay E, Bilginoglu A, Sozmen NN, Zeydanli EN, Ugur M, Vassort G, Turan B: Intracellular free zinc during cardiac excitation-contraction cycle: calcium and redox dependencies. Cardiovascular research 2010, 89(3):634-642

26. Davidoff AJ, Rodgers RL: Insulin, thyroid hormone, and heart function of diabetic spontaneously hypertensive rat. Hypertension 1990 15(6 Pt 1):633-642.

27. Dillmann WH: Diabetes mellitus induces changes in cardiac myosin of the rat. Diabetes 1980, 29(7):579-582.

28. Joseph T, Coirault C, Dubourg O, Lecarpentier Y: Changes in crossbridge mechanical properties in diabetic rat cardiomyopathy. Basic Res Cardiol 2005, 100(3):231-239.

29. Rundell VL, Manaves $V$, Martin AF, de Tombe PP: Impact of beta-myosin heavy chain isoform expression on cross-bridge cycling kinetics. Am J Physiol Heart Circ Physiol 2005, 288(2):H896-903.

30. Fitzsimons DP, Patel JR, Moss RL: Role of myosin heavy chain composition in kinetics of force development and relaxation in rat myocardium. J Physiol 1998, 513(Pt 1):171-183.
31. Herron TJ, Korte FS, McDonald KS: Loaded shortening and power output in cardiac myocytes are dependent on myosin heavy chain isoform expression. Am J Physiol Heart Circ Physiol 2001, 281(3):H1217-1222.

32. Korte FS, Herron TJ, Rovetto MJ, McDonald KS: Power output is linearly related to $\mathrm{MyHC}$ content in rat skinned myocytes and isolated working hearts. Am J Physiol Heart Circ Physiol 2005, 289(2):H801-812.

33. Godt RE, Lindley BD: Influence of temperature upon contractile activation and isometric force production in mechanically skinned muscle fibers of the frog. J Gen Physiol 1982, 80(2):279-297.

34. Palmer BM, Fishbaugher DE, Schmitt JP, Wang Y, Alpert NR, Seidman CE, Seidman JG, VanBuren P, Maughan DW: Differential cross-bridge kinetics of FHC myosin mutations R403Q and R453C in heterozygous mouse myocardium. Am J Physiol Heart Circ Physiol 2004, 287(1):H91-99.

35. Noguchi T, Hunlich M, Camp PC, Begin KJ, El-Zaru M, Patten R, Leavitt BJ, Ittleman FP, Alpert NR, LeWinter MM, et al: Thin-filament-based modulation of contractile performance in human heart failure. Circulation 2004, 110(8):982-987.

36. VanBuren P, Alix SL, Gorga JA, Begin KJ, LeWinter MM, Alpert NR: Cardiac troponin $\mathrm{T}$ isoforms demonstrate similar effects on mechanical performance in a regulated contractile system. Am J Physiol Heart Circ Physiol 2002, 282(5):H1665-1671.

37. Palmer BM, Chen Z, Lachapelle RR, Hendley ED, LeWinter MM: Cardiomyocyte function associated with hyperactivity and/or hypertension in genetic models of LV hypertrophy. Am J Physiol Heart Circ Physiol 2006, 290(1):H463-473.

38. Palmer BM, Moore RL: Excitation wavelengths for fura 2 provide a linear relationship between $[\mathrm{Ca}(2+)]$ and fluorescence ratio. Am J Physio/ Cell Physiol 2000, 279(4):C1278-1284.

39. Reiser PJ, Kline WO: Electrophoretic separation and quantitation of cardiac myosin heavy chain isoforms in eight mammalian species. Am J Physiol 1998, 274(3 Pt 2):H1048-1053.

40. Kay AR: Detecting and minimizing zinc contamination in physiological solutions. BMC Physio/ 2004, 4:4.

41. Fredersdorf S, Thumann C, Zimmermann WH, Vetter R, Graf T, Luchner A Riegger GA, Schunkert H, Eschenhagen T, Weil J: Increased myocardial SERCA expression in early type 2 diabetes mellitus is insulin dependent: In vivo and in vitro data. Cardiovascular diabetology 2012, 11:57.

42. Thackeray JT, Radziuk J, Harper ME, Suuronen EJ, Ascah KJ, Beanlands RS, Dasilva JN: Sympathetic nervous dysregulation in the absence of systolic left ventricular dysfunction in a rat model of insulin resistance with hyperglycemia. Cardiovascular diabetology 2011, 10:75.

43. Fulop N, Marchase RB, Chatham JC: Role of protein O-linked $\mathrm{N}$-acetyl-glucosamine in mediating cell function and survival in the cardiovascular system. Cardiovascular research 2007, 73(2):288-297.

44. Nass N, Bartling B, Navarrete Santos A, Scheubel RJ, Borgermann J, Silber RE, Simm A: Advanced glycation end products, diabetes and ageing. Zeitschrift fur Gerontologie und Geriatrie 2007, 40(5):349-356.

45. Samant SA, Courson DS, Sundaresan NR, Pillai VB, Tan M, Zhao Y, Shroff SG, Rock RS, Gupta MP: HDAC3-dependent reversible lysine acetylation of cardiac myosin heavy chain isoforms modulates their enzymatic and motor activity. J Biol Chem 2011, 286(7):5567-5577.

46. Andrews GK: Cellular zinc sensors: MTF-1 regulation of gene expression. Biometals 2001, 14(3-4):223-237.

47. Gunther V, Lindert U, Schaffner W: The taste of heavy metals: gene regulation by MTF-1. Biochimica et biophysica acta 2012, 1823(9):1416-1425

48. Guo L, Lichten LA, Ryu MS, Liuzzi JP, Wang F, Cousins RJ: STAT5-glucocorticoid receptor interaction and MTF-1 regulate the expression of ZnT2 (Slc30a2) in pancreatic acinar cells. Proceedings of the National Academy of Sciences of the United States of America 2010, 107(7):2818-2823.

49. Kumar SD, Vijaya M, Samy RP, Dheen ST, Ren M, Watt F, Kang YJ: Bay BH. Tay SS: Zinc supplementation prevents cardiomyocyte apoptosis and congenital heart defects in embryos of diabetic mice. Free radical biology \& medicine; 2012, 53(8):1595-1606.

50. Lichtlen $P$, Wang Y, Belser T, Georgiev O, Certa U, Sack R, Schaffner W: Target gene search for the metal-responsive transcription factor MTF-1. Nucleic acids research 2001, 29(7):1514-1523.

51. Foster M, Samman S: Zinc and redox signaling: perturbations associated with cardiovascular disease and diabetes mellitus. Antioxidants \& redox signaling 2010, 13(10):1549-1573. 
52. Singh J, Chonkar A, Bracken N, Adeghate E, Latt Z, Hussain M: Effect of streptozotocin-induced type 1 diabetes mellitus on contraction, calcium transient, and cation contents in the isolated rat heart. Ann N Y Acad Sci 2006, 1084:178-190.

53. Nakagawa M, Kobayashi S, Kimura I, Kimura M: Diabetic state-induced modification of $\mathrm{Ca}, \mathrm{Mg}$, Fe and $\mathrm{Zn}$ content of skeletal, cardiac and smooth muscles. Endocrinol Jpn 1989, 36(6):795-807.

54. Maret W: Zinc and sulfur: a critical biological partnership. Biochemistry 2004, 43(12):3301-3309.

55. Soinio M, Marniemi J, Laakso M, Pyorala K, Lehto S, Ronnemaa T: Serum zinc level and coronary heart disease events in patients with type 2 diabetes. Diabetes care 2007, 30(3):523-528.

doi:10.1186/1475-2840-11-135

Cite this article as: $Y$ i et al:: Zinc-induced cardiomyocyte relaxation in a

rat model of hyperglycemia is independent of myosin isoform.

Cardiovascular Diabetology 2012 11:135.

\section{Submit your next manuscript to BioMed Central and take full advantage of:}

- Convenient online submission

- Thorough peer review

- No space constraints or color figure charges

- Immediate publication on acceptance

- Inclusion in PubMed, CAS, Scopus and Google Scholar

- Research which is freely available for redistribution 